(Aus der deutsch-österreich. Universitätsnervenklinik in Graz

[Vorstand Prof. Dr. Fritz Hartmann].)

\title{
Studien über den Einfluß der Großhirntätigkeit auf die Magensaftsekretion des Menschen.
}

\author{
Von \\ Privatdoz. Dr. Heinz Schrottenbach, \\ ordentl. Assistent am Institute.
}

Mit 32 Textabbildungen.

(Eingegangen am 15. März 1921.)

Während in früherer Zeit der Begriff der ,Seelenkrankheiten“, "Gemütserkrankungen" usw. die psychiatrische Wissenschaft fast ausschließlich beherrschte - von welchen Vorstellungen übrigens noch immer ein Teil auch forschender Ärzte beherrscht wird - haben Forschungsergebnisse jüngerer Zeit immer mehr Anhaltspunkte dafür ergeben, daß die Funktionen der "Seele" eben auch nichts anderes sind, als äußere Erscheinungen von Lebensvorgängen im Organismus, insonderheit im Nervensystem.

Diese sich allmählich durchsetzende Erkenntnis wurde besonders durch unsere allmählich wachsende Kenntnis von den Funktionen des vegetativen Nervensystems gefördert. So kennen wir bereits ziemlich genau die Wechselwirkungen zwischen Affekten und Einstellungsvorgängen des vasovegetativen Nervenapparates; ja wir können sogar das Zentrum dieses Mechanismus mit großer Wahrscheinlichkeit in die phylogenetisch alte Region des Zwischenhirns (Hypothalamus) verlegen (Karplus und Kreidl, Schrottenbach). Wir dürfen nach den bisherigen Forschungsergebnissen bereits mit Sicherheit annehmen, daß jeder Sinneseindruck, jeder Assoziationsvorgang sowie alle motorischen Äußerungen nervöser Vorgänge von solchen Einstellungsvorgängen im Gebiete des vegetativen Nervensystems begleitet sind.

Es ist jedoch noch nicht gelungen, die Wechselwirkungen, welche zwischen Großhirnleistung und Leistung des vagosympathischen Apparates angenommen werden dürfen, auch nur einigermaßen befriedigend in der Richtung hin aufzuklären, die Gesetze wechselseitiger Abhängigkeit und damit gegenseitig wohl vorhandener Verursachung aufzudecken. Daß solche gegenseitige Kausalitätsbeziehungen bestehen, 
wissen wir sehr wohl aus der Pathologie: Die depressive Verstimmung Magenkranker, die ,,cholerische" Stimmungslage bei Erkrankungen der Leber sind altbekannte Tatsachen, ebenso wie etwa die Angstzustände Herzkranker oder die häufig beobachtete Euphorie tuberkulöser Kranker. Daß bei allen diesen und noch vielen anderen, vielleicht allen Erkrankungen, welche in den Stoffwechselhaushalt des Organismus eingreifen, auch das vegetative Nervensystem mit irritiert wird, darf wohl ohne weiteres angenommen werden. Inwieweit jedoch die tatsächlich oft einwandfrei zu beobachtenden Veränderungen zunächst der Stimmungslage, dann aber auch komplexer Großhirnleistungen von solchen Irritationen des vagosympathischen Systems beeinflußt sind oder gar abhängen, darüber lassen sich bisher nur Meinungen oder bestenfalls Hypothesen äußern, da die experimentellen Grundlagen für die Aufklärung der physiologisch vorhandenen Verhältnisse keineswegs genügen.

Die Kenntnis aller dieser zweifellos vorhandenen GesetzmäBigkeiten wäre für das Verständnis des ,psychischen“" Geschehens überhaupt von enormer Wichtigkeit; wissen wir doch nur beispielsweise seit Ziehen, daß unsere gesamte Assoziationstätigkeit von der Gefühlsbetonung der zur Auswahl stehenden assoziativ verwandten Vorstellungen - und jede Vorstellung ist gefühlsbetont - in maßgebender Weise beeinflußt wird.

Das weitere Studium der Funktionen des vegetativen Nervensystems muß also zu aussichtsreichen Zielen führen und die im folgenden niedergelegten Untersuchungen sollen einen Baustein zu dem hier aufzuführenden großen Gebäude darstellen.

Eine ganze Reihe von Forschern haben sich bereits damit beschäftigt, die Sekretionsbedingungen der Verdauungsdrüsen, insbesondere der Speichel- und Magendrüsen, im Tierexperiment und am Menschen zu untersuchen und auch die Beeinflussung dieser Leistungen durch das Nervensystem zu studieren. Immer mehr rang sich bei dieser Forschungsrichtung die Utberzeugung durch, daß diese Leistungen im weitesten Maße vom Nervensystem abhängig seien, was besonders seit Pawlows und seiner Schule grundlegenden Arbeiten eine für den tierischen Organismus vollkommen bewiesene Tatsache geworden ist.

Die Sekretionsbedingungen des Magens sind im Tierexperiment häufig untersucht worden. Blondlot mißt der Salivation, den Kauund Schlingakten, große Bedeutung für die Hervorrufung der Magensekretion zu. Wright sieht eine der wesentlichsten Aufgaben des Speichels darin, die Magensaftsekretion anzuregen. Auch Rollet und Sticker sind ähnlicher Anschauung gewesen. 
Dagegen fanden schon 1852 Bidder und Schmidt, daß bei fastenden Tieren schon der bloße Anblick der Speise, also ein reiner Sinneseindruck, welcher zunächst als ein für den Drüsenapparat des Magens vollkommen inadäquater Reiz aufzufassen ist, die Magensaftsekretion steigert. Longet stellte dann fest, daß die Geschmacksempfindung bereits Sekretion der Magendrüsen erzeugen könne, bevor noch die Speise in den Magen gedrungen sei. Richet fand, daß sich beim Hunde mit Magenfistel dann, wenn man den Hund mit Fleisch necke, die Magenschleimhaut röte und Magensaft aus der Fistel auszufließen beginne. Chigin berichtet auf Grund seiner Untersuchungen, daß unter normalen Umständen die Sekretion im Magen des Hundes überhaupt zunächst auf Grund eines ,,psychischen Reflexes" erfolge und erst dann von dem aus der Nahrung gebildeten Pepton fortgesetzt werde.

Die zahlreichen Arbeiten Pawlows und seiner Schule konnten den großen Einfluß der Leistungen des Zentralnervensystems auf die Tätigkeit der Magen- und Speicheldrüsen in grundlegender Weise feststellen; Pawlows Untersuchungen führten zur Aufstellung des Begriffes der ,bedingten Reflexe“, deren maßgebender Einfluß auf die Tätigkeit besonders der Speicheldrüsen von ihm und seinen Schülern (Kettscher, Sanotzki, Lobasoff, Schumowa-Simanowskaja, Boldireff, Woskoboinikowa-Grauström, Wassilieff, Kascherininowo u. a. m.) genauestens festgestellt wurde. Als bedingten Reflex bezeichnet Pawlow folgende Erscheinung: Wenn bei einem Hunde mit Speichelfistel einige Male hintereinander gleichzeitig mit dem Darreichen der Nahrung ein Sinnesreiz (optisch, akustisch, taktil, olfaktorisch) gesetzt wird, so genügt nach einigen derartigen Versuchen dieser Sinnesreiz bereits allein, um Speichelsekretion hervorzurufen.

In Hinsicht der Tätigkeit der Magendrüsen stellten Pawlow und seine Schule am ösophagotomierten Hunde ungefähr folgendes fest: Der Eßakt ist ein sehr wirksames Stimulans bei der Erzeugung des Magensaftes. Rein mechanische Reizung der Mundschleimhaut oder der Magenschleimhaut allein vermag die Magendrüsen nicht in Tätigkeit zu setzen, ebensowenig Reizung der Mundschleimhaut mit sauren, salzigen und bitteren Stoffen, Pfeffer, Senf.

Dagegen kann der bloße Anblick der Nahrung Magensaftabsonderung hervorrufen, jedoch nur bei lebhaften, gefräßigen Hunden. Hierbei kann die Menge des abgesonderten Magensaftes sogar größer sein als bei einer Scheinfütterung (Fütterung des ösophagotomierten Hundes, bei welchem die verschluckte Nahrung zur Oesophagusfistel herausfällt).

Das mächtigste Stimulans für die sekretorischen Magennerven ist der Appetit; der ,große sekretorische Effekt" desselben wird durch 
das ,"psychische Moment" bedingt, das heißt „durch das leidenschaftliche Verlangen nach Nahrung und die Freude an ihrem Genuß". Durch die Einführung der Nahrung in den Magen allein wird nur eine mangelhafte Sekretion angeregt, die Verdauungsarbeit des Magens erscheint gering; ist dagegen bei der Aufnahme der Nahrung dieses „psychische Moment" mit im Spiel, so kommt es zur Produktion eines überaus verdauungskräftigen Sekretes.

Bickel suchte dann diesen ,psychischen Faktor" Pawlows etwas näher zu analysieren und insbesondere auch die psychische Hemmung der Magendrüsentätigkeit experimentell festzustellen, indem er den ösophagotomierten Fistelhund einmal während der Scheinfütterung, dann auch nach Ende derselben durch Vorzeigen einer Katze reizte, worauf der Hund mit lebhaftem Zornaffekt reagierte. Auf Grund dieser Versuche stellte Bickel fest, daß, durch starke Affekte die nervösen Apparate des Magens so nachdrücklich verstimmt werden können, daß die mit der Aufnahme der Nahrung Hand in Hand gehenden nervösen Erregungen nicht mehr genügen, um die normale Saftbildung anzuregen." Ferner, daß Affekte einen gewaltigen hemmenden Einfluß auf die bereits eingeleitete Magensaftsekretion haben. „Wie ein Reiz eine Reflexbewegung, die durch einen anderen Reiz hervorgerufen wird, verhindern kann, so vermag auch ein psychischer Vorgang in den Erfolg eines andern hemmend einzugreifen, auch wenn dieser Erfolg als solcher niemals dem betreffenden Individuum Bewußtseinsinhalt wird."

Aus diesem Schlußsatz geht noch klarer als aus Pawlows Arbeiten der Gewinn für das Verständnis der ,psychischen“ Vorgänge an den Versuchstieren hervor, welchen diese Forschungsrichtung ge. bracht hat. Wir sind durch sie in den Stand gesetzt, ,psychische Vorgänge" an 'Tieren aus körperlichen Begleiterscheinungen einwandfrei, objektiv festzustellen; ja, es wäre sogar möglich, eine Art von quantitativer Feststellung der Dauer und vielleicht auch des Grades der Affekte durch vergleichende Messung und Zeitbestimmung der durch sie verursachten Veränderungen der Magensaftsekretion zu erhalten, was meines Wissens bisher von diesem Gesichtspunkte aus nicht versucht wurde.

Nikolai hat zwar für die graphische Darstellung der Speichelsekretion am Hunde eine für obiges Problem sehr geeignete Methode in Anwendung gebracht, jedoch damit lediglich die bedingten Reflexe studiert, welche auf die Speicheldrüsen wirken. Er stellt fest, daß ein bedingter Reflex durch öftere rasch aufeinanderfolgende Inanspruch. nahme erlösche, daß jedoch die Vernichtung eines bedingten Reflexes in keiner Weise die andern bedingten Reflexe beeinflusse; ferner, daß sich der erloschene bedingte Reflex nach verschieden langer Zeit von selbst wieder herstelle. Man könne ihn aber sofort wieder her- 
stellen, wenn man ihn ,einmal wirksam werden lasse", d. h. dem Hund nach Hervorrufung des Reflexes wirklich Nahrung reiche. Wenn ein bestimmtes Nahrungsmittel längere Zeit keinen unbedingten Reflex von der Mundhöhle her auslösen konnte, so verschwindet der zugehörige bedingte Reflex (durch Zeigen dieses Nahrungsmittels) vollkommen; er stehe also in einem Abhängigkeitsverhältnis vom unbedingten Reflex. Ein Reiz werde durch einen zweiten gleichzeitig gesetzten, sei es gleichoder ungleichartigen Reiz, gehemmt.

Auch aus Versuchen am Menschen liegen zahlreiche Unter. suchungen über die Sekretionsbedingungen des Magensaftes vor; hier soll nur jener Teil derselben, welcher für vorliegende Arbeit in Betracht kommt, referiert werden, nämlich jene Arbeiten, welche die Beziehungen des Nervensystems zur Magensaftsekretion berühren.

Beaumont kommt zum Schlusse, daß ,das Kauen, Einspeicheln und Verschlucken der Nahrung abstrakt genommen, die Verdauung der Speisen keineswegs bewirke; oder mit andern Worten, daß, wenn die Speisen auf anderem Wege fein genug verteilt direkt in den Magen kommen, ohne jener Behandlung vorher teilhaftig geworden zu sein sie so leicht und so vollkommen verdaut werden, als wären sie so vorbereitet genossen worden."

Dagegen schreibt Biernacki dem Durchgang der Speisen durch die Mundhöhle eine wesentliche Rolle für die Magensaftsekretion zu; der entleerte Mundspeichel selbst und der Speichel, der nach dem Verschlucken der Speisen von der Mundhöhle her in den Magen gelangen, seien demgegenüber von untergeordneter Bedeutung. Dem Speichel komme nur eine indirekt stimulierende Wirkung auf die Magensaftsekretion zu.

Nach Troller kommt Steigerung der Magensaftsekretion durch Kauen chemischer Reizmittel (Citronenscheiben und Senf), physiologischer (Nahrungsmittel) und indifferenter Stoffe (Gummi, Linnen) zustande. Beim Kauen von Nahrungsmitteln erhält Troller 2-4 mal größere Mengen von Magensaft, als bei den beiden anderen Versuchen, und verschiedene Arten von Nahrungsmitteln ergaben verschiedene Mengen verschieden säurehaltigen Magensaftes; so lieferte Fleisch im allgemeinen $10-20 \mathrm{ccm}$ Saft mehr als Brot.

Nach Schüle kann schon vom Munde aus eine intensive Sekretion von Magensaft hervorgerufen werden. Nicht die Reaktion der Ingesta sei maßgebend, sondern der Umstand, daß überhaupt gekaut werde. Während des Kauens werden die Drüsen des Magens zu erhöhter Tätigkeit angeregt. Ein reiner „Appetitsaft" im Sinne Pawlows finde sich beim Menschen nur selten oder gar nicht. Das bloße ,Necken mit der Nahrung" ergebe beim Menschen keinen Effekt. Schüle nimmt an, daß die von Pawlow beim Hunde gefundenen Verhältnisse beim 
Menschen nicht existieren, weil ,sich sein Interesse nicht in genügend hohem Grade auf die Nahrung konzentriere".

$\mathrm{Zu}$ Schüles Versuchsergebnissen ist $\mathrm{zu}$ bemerken, daß sie nach Ausheberung des Magens gewonnen sind, einem Verfahren, welches wegen der damit stets verbundenen größeren oder geringeren Unlustaffekte keineswegs geeignet erscheint, die in Rede stehenden Fragen zu lösen, da die Unlust an und für sich die Magensaftsekretion schon beim Tier hochgradig zu beeinflussen vermag (Bickel).

Dagegen experimentierte Hornbog an einem 5jährigen Knaben mit Oesophagusstriktur und Magenfistel, bei welchem aus der Mundhöhle keinerlei Nahrung in den Magen gelangte. Der bei den Versuchen aus der Fistel ausfließende Magensaft wurde in Portionen von $5 \mathrm{Mi}$ nuten Dauer gesammelt. Berücksichtigt wurden sezernierte Menge, Gesamtacidität und Digestionskraft des gewonnenen Magensaftes.

Hornbog kam zu folgenden Ergebnissen: Der Anblick der Speise hatte auf keine Weise, auch nicht mit entsprechenden Suggestionsvorstellungen beim hungernden Kinde, Magensaftsekretion zur Folge. Da dieser Befund mit Pawlows Resultaten am Hunde in Widerspruch steht, nimmt Hornbog an, daß der Zornaffekt, welcher beim Kinde sofort auftrat, wenn es die vorgezeigte Speise nicht sofort bekam, genügt haben dürfte, um die Saftsekretion zu hemmen.

Auf Kauen und Hinunterschlucken der Nahrung (dieselbe wurde nach wenigen Sekunden wieder heraufgewürgt) trat nach 6 bis 7 Minuten ein ziemlich reichlicher Saftausfluß aus der Magenfistel auf, dagegen löste mit Widerwillen in den Mund genommene Milch keine Saftsekretion aus. Der Kauakt an sich schien die Magendrüsen nicht in Tätigkeit versetzen zu können (Kauen von Gummi). Mehr oder minder angenehmer Geschmack der Speisen war nicht ohne Einfluß auf die Magensaftsekretion; das Kauen übelschmeckender Speisen löste keine nennenswerte Sekretion aus. Die Ursache der starken Steigerung der Sekretion bei Fleischfütterung, der minimalen oder ausbleibenden bei Milchfütterung sucht Hornbog in dem Umstande, daß die Speise das eine Mal mit Appetit, das andere Mal mit Widerwillen genommen wurde.

In den positiven Versuchen begann die Saftabsonderung, wie schon gesagt, nach 6-7 Minuten, stieg dann rasch an, um innerhalb der nächsten 10 Minuten das Maximum zu erreichen; dann nahm sie allmählich ab und war gewöhnlich 40 Minuten nach Beginn des Versuches beendet. Bisweilen erfolgte die Abnahme auch rascher, so daß der ganze Sekretionsakt nicht länger als 10 Minuten dauerte.

Roeder und Sommerfeld wiederholten die Scheinfütterungsversuche Pawlows an einem ösophagotomierten Kinde mit Magenfistel. Es zeigte sich dabei, daß die Beobachtungen am Hunde auch 
für den Menschen zutreffen. Außerdem konnte eine gewisse Abhängigkeit der Intensität der Magensaftbildung von dem jeweiligen psychischen Allgemeinzustande des Kindes nachgewiesen werden.

Umber machte an einem 59jährigen Manne mit Speiseröhrenverengerung und Magenfistel die Beobachtung, daß Geschmacksreiz ohne Kauakt (Ausfüllen des Mundes mit $20 \mathrm{ccm}$ Kognak) Sekretion von Magensaft hervorrief, während Kauakt ohne Geschmacksreiz (Gummikauen) und Kauakt mit Geschmacksreiz (Tabakkauen) keinen Tropfen Magensaft zutage förderte.

Bickel kommt nach Versuchen an einem Mädchen mit Magenfistel zu folgenden Ergebnissen und Schlüssen: Für die Sekretbildung im menschlichen Magen kommen Reize einer doppelten Provenienz in Frage, und zwar erstens Reize, welche allein durch die Berührung der Schleimhaut des Verdaungskanals mit den Ingestis bestehen, und zweitens Reize, welche ,, a uf andere sensible Nerven, besonders auf bestimmte kapitale Sinnesorgane ausgeübt werden". In seinen Versuchen blieben akustische Reize (Unterhaltung über eßbare Gegenstände) ohne Einfluß auf die Magensaftsekretion, auch optische und taktile (Kauen von Gummi) Reize wirkten nicht sicher; dagegen trat nach Geruchs- und Geschmacksreizen stets Saftbildung auf, wobei die Qualität des Geruches und Geschmackes anscheinend ziemlich gleichgültig war. (Geruch: Maggiwürze, Essig, Ammoniak, Asa foetida, aromatische Öle; Geschmack: Chininum hydrochlor., Kochsalz, Zucker.)

Bei Scheinfütterungsversuchen am selben Mädchen fand Bickel zunächst eine Latenzzeit von 4-5 Minuten; er unterscheidet dann eine Sekretionsphase während des Kauens und endlich eine Phase der Absonderung, welche das Kauen überdauert. Die Quantität des abgesonderten Magensaftes hänge ab von der Intensität des gustatorischen adäquaten Reizes und sei im allgemeinen großen Schwankungen unterworfen, während die qualitative Zusammensetzung des Sekretes annähernd gieich bleibe. Die Sekretmenge sei abhängig vom Nervensystem, vom Wassergehalt und Chlorgehalt des Körpers und von der Art der die Sekretion auslösenden Nahrungsstoffe.

Bogen stellt nach Versuchen an einem $3^{1 / 2}$ jährigen Knaben mit totaler Verätzungsstenose des Oesophagus und Magenfistel fest, daß auch auf die bloße suggestiv erzeugte Vorstellung von Fleisch oder von anderen Nahrungsmitteln eine Magensaftsekretion ausgelöst werden kann (psychisches Sekret). Ferner stellte er "Assoziationsversuche" durch Blasen einer kleinen Trompete während des Fütterns an, was wohl besser als Versuch der Erzeugung eines bedingten Reflexes zu bezeichnen wäre, und erhielt bei bloßem Blasen der Trompete unter 10 Versuchen 7 mal 
Studien tb. d. Einfl. d. Großhirntätigk. auf d. Magensaftsekretion d. Menschen. 261

ein positives, $3 \mathrm{mal}$ ein negatives Resultat. Die Erregung von Zorn oder Schreck hemmte stets die Magensaftsekretion.

Nach Bofinger zeigen, ,gerade die mit der Verdauung zusammenhängenden Vorgänge eine so weitgehende Wechselwirkung mit der Psyche, vor allem mit dem als Stimmung bezeichneten Teil des psychischen Lebens, wie wir dies sonst nur noch beim Herzen sehen". Unter Wechselwirkung meine er dabei ebensosehr die Beeinflussung der Stimmung und der Vorstellungen durch den jeweiligen Zustand der Verdauungsorgane als umgekehrt die Hemmung oder Förderung der Verdauungstätigkeit durch psychische Einflüsse.

Herz and Sterling ließen einem gastrostomierten Kranken, welchem sie vorher den Magen ausgespült hatten, in Seh- und Riechweite ein Kotelett zubereiten und unterhielten sich gleichzeitig mit ihm über schmackhafte Speisen; während dieser Zeit floß aus der Fistel $14 \mathrm{ccm}$ salzsäurehaltige Flüssigkeit (Appetitsaft Pawlows). Sie konnten die Saftsekretion auch während des Kauens und Schluckens bestätigen. Durch Unlustgefühle wurde die Magensaftabsonderung fast vollständig gehemmt.

Grandauer kommt auf Grund seiner Versuche über die Magensaftabsonderung, welche in wiederholter Ausheberung der Versuchspersonen unter besonderen Kautelen bestanden, zu der Anschauung, daß ,die Psyche die Magensaftsekretion in positivem und negativem Sinne beherrsche“. Der Einfluß der Psyche erstrecke sich in erster Linie auf die beiden ersten Sekretionsphasen (1. Verlangen nach der Speise, Sehen, Riechen derselben; 2. Schmecken, Kauen, Schlucken). Wenn man aber bedenke, daß während der dritten Phase, wenn sich die aus den Reizen der Nahrungsstoffe resultierende Saftbildung (endogene Saftbildung nach Karst) abspiele, meistens die zweite Saftphase noch nicht abgeschlossen sei und weiterhin, daß nach $\mathrm{Pawlows}$ Versuchen der psychisch bedingte Saft zugleich einen ,Zündstoff“" für spätere Saftsekretion abgebe, so könne man zu der Schlußfolgerung kommen, daß sich der Einfluß der Psyche fast auf die ganze Breite der sekretorischen Tätigkeit des Drüsenapparates erstrecke. Grandauer erinnert an die wohlbekannten Erscheinungen des Erwachens des Appetites erst während des Essens, des Vergehens der EBlust vor Ärger.

Auch Skray versuchte durch Magensondierungen zu Schlüssen über die Wirkung psychischer Faktoren auf die Magensaftsekretion zu kommen und meint, daß durch psychische Momente (Erregungszustände vor und während der Sondierung) die Acidität des Mageninhaltes nach Probefrühstück beeinflußt werden könne; die hierbei auftretenden Differenzen der Acidität seien im allgemeinen gering (selten über 10). 
Bechterew hält dafür, daß sich, ,der mächtigste und nächste Erreger der sekretorischen Nerven der Magendrüsen in der gleichzeitigen Reizung des Auges, des Gehörs, (des Tastsinns?) des Geruches und Geschmackes durch die Nahrung finde ${ }^{4}$, hauptsächlich der beiden letzteren. Auch der Appetit gehöre zu den mächtigsten Erregern der Magensekretion. Ein starker Appetit beim Essen bedeute, daß vom Anbeginn des Essens an eine reichliche Ausscheidung des Magensaftes stattfand. Fehle der Appetit, so sei auch der Anfangssaft nicht vorhanden.

Aus Pawlows Darlegungen gehe mit Sicherheit hervor, daß die Hirnrinde als Organ der psychischen Tätigkeit einen außerordentlichen Einfluß auf die Vorgänge der Magensaftausscheidung üben müsse. Diese Annahme werde auch experimentell als vollkommen zutreffend erhärtet, denn Bufalini beobachtete den Eintritt von Magensaftausscheidung unter dem Einfluß der Hirnrinde.

Die in Bechterews Laboratorium von Gerwer angestellten Versuche, nach welchen beim Hunde ein mit dem kontralateralen Vagus in vorwiegender Verbindung stehendes Magensaftsekretionszentrum am vorderen unteren Teile des Gyrus sigmoideus vor dem Sulcus cruciatus bestehen soll, wurden von Pawlow und Tichimirow nachgeprüt; sie konnten jedoch die Ergebnisse Gerwers nicht bestätigen, da bei ihren Hunden nach Exstirpation dieses Zentrums sowohl beim Anblick der Nahrung als auch bei Scheinfütterung Magensaftsekretion auftrat.

Auch von den subcorticalen Zentren aus soll nach Gerwer eine Beeinflussung der Magensaftabsonderung möglich sein, insbesondere vom vorderen Vierhügelpaar; auch zum Thalamus sollen Beziehungen bestehen.

Trotz aller dieser zahlreichen Untersuchungen, insbesondere auch der ausgedehnten Tierexperimente der Pawlow. Schule, kann eine abgeschlossene Theorie der Magensaftsekretion in ihrer Abhängigkeit vom Nervensystem heute noch nicht aufgestellt werden (Allers).

Aus der Durchsicht der über alle diese Fragen vorhandenen Literatur geht zunächst hervor, daß bezügliche Untersuchungen in ausreichender Anzahl und methodisch entsprechend durchgearbeitet eigentlich nur an Tieren, im besonderen am Hunde, angestellt wurden. Analoge Untersuchungen am Menschen sind nur in verhältnismäßig geringer Anzahl vorhanden und auch diese sind nicht durchwegs methodisch einwandfrei.

Bei dem großen Einfluß der Affekte auf die Magensaftabsonderung, der schon beim Tier experimentell festgestellt ist, müssen alle jene Untersuchungen, welche mittels Ausheberung des Magens angestellt wurden, von vornherein für die Analyse der Beziehungen von Großhirn- 
tätigkeit und Magensaftsekretion ausgeschaltet werden, da die Fehlerquelle, welche durch den ängstlich-ablehnenden Affekt vor oder während der Sondierung gegeben ist, $\mathrm{zu}$ groß und zu veränderlich erscheint.

Es bleiben also strenggenommen für die Beurteilung der bezüglichen Verhältnisse am Menschen nur jene Untersuchungen verwertbar, welche am Magenfistelmenschen angestellt wurden. Aber auch sie lassen eine Reihe von wichtigen Fragen offen oder nicht genügend erläutert.

So erscheinen vor allem die zeitlichen Verhältnisse der Magensekretion keineswegs genügend geklärt. Wenn wir bei Hornbog und bei Bickel lesen, daß diese eine Latenzzeit von 6-7, bzw. 4-5 Minuten zwischen Reiz und Beginn des Sekretabflusses fanden, so interessiert zunächst die verhältnismäßige Länge dieser Latenzzeit, da doch die zumindest ähnlichen nervösen Bedingungen unterworfene Speichelsekretion nach viel kürzeren Latenzzeiten zu beobachten ist (Salivation beim Hungernden auf Vorstellung, Anblick, Geruch von Speisen). Ferner ist die relativ große Differenz zwischen den von den beiden Forschern gefundenen Latenzzeiten auffällig, vielleicht individuellen Schwankungen unterworfen.

Die Methodik Hornbogs, das abfließende Magensekret in Portionen von 5 zu 5 Minuten Dauer aufzufangen und zu messen, erscheint für das Studium feiner differenzierter nervöser Leistungen, und als solche ist die Magensekretion bei ihrer Beeinflußbarkeit von allen möglichen Sinnesgebieten aus wohl anzusehen, doch zu wenig fein abgestimmt. Man bedenke, wie empfindlich dagegen die Methoden zum Studium der Vasomotorentätigkeit (Plethysmographie, Elektrokardiogramm usw.) sind, und weiterhin, daß für die Funktion der Magendrüsen vasomotorische Einstellvorgänge zweifellos als mitbestimmend angenommen werden müssen [Rötung der Magenschleimhaut bei Sekretion (Richet)]. Es erscheint daher keineswegs unangebracht, die an und für sich wertvollen Versuche mit verfeinerter Methodik zu wiederholen.

Der Einfluß der bedingten Reflexe auf die menschliche Magensekretion wurde systematisch nur von Bogen untersucht und verdient bei der Wichtigkeit, welche die Frage bedingter Reflexe für das Verständnis nervösen Geschehens (z. B. „reflektorischer Handlungen“) überhaupt hat, wiederholte Untersuchung und Nachprüfung.

Endlich erscheint die Frage, inwieweit Stimmungslage und Gemeingefühle - darunter verstehe ich Roeders und Sommerfelds „psychischen Allgemeinzustand" - die Magensekretion beeinflussen, der weiteren Untersuchung an geeigneten Fällen nicht nur vom wissenschaftlichen, sondern auch vom praktischen Standpunkte aus würdig. 
Die Untersuchungen, über welche berichtet werden soll, wurden an zwei Individuen männlichen Geschlechts angestellt, deren Krankengeschichten im folgenden auszugsweise mitgeteilt werden, soweit die Angaben in denselben für die Beurteilung der angestellten Versuche in Betracht krommen.

Die Gelegenheit, an diesen beiden Patienten der chirurgischen Universitätsklinik vorliegende Versuche anstellen zu können, verdanke ich dem liebenswürdigen Entgegenkommen des Vorstandes derselben, Hofrat Prof. Dr. v. Hacker, welchem an dieser Stelle meinen besten Dank auszusprechen mir eine angenehme Pflicht ist.

Krankengeschichte I.

Name: K. J.

Alter, St and, Beruf: 5 J., unehl. Wäscherinskind.

Tag der Aufnahme: 28. VII. 1909.

Abteilung: chirurg. Klinik.

Diagnose: Strictura oesophagi.

Ausgang der Behandlung, Tag des Abganges: 17. I. 1912, geheilt.

A nam nese Das Kind hat sich am 13. VI. 1908 mit Laugenessenz den Oesophagus verätzt. Es wurde in das Klagenfurter Krankenhaus gebracht, woselbst eine Magenfistel angelegt werden mußte. Inzwischen hat es Masern und Bronchitis durchgemacht. Das Kind hat ofter Fieber, hier und da Nachtschweiße. In der letzten Zeit abgemagert. Vor der Fistelanlegung soll es sehr abgemagert gewesen sein, hat sich aber während der Ernährung von der Fistel aus erholt.

Spitalaufenthalt in Klagenfurt: I. vom 13. bis 24. Juni 1908. 2. vom 24. VI. bis 17 . VII. 1909 .

Im März Operation. War immer etwas kränklich. Wird behufs Operation auf die hiesige Klinik geschickt.

6. VIII. Operation fec. Dr. Fischer: Versuch, einen Faden ohne Ende einzulegen. Das Durchführen einer Darmsaite gelingt erst nach einiger Mühe im Oesophagoskop, jedoch ist es nicht möglich, das Ende der Saite aus der Magenfistel herauszubekommen.

15. X. Mehrere Bougierungsversuche mit Darmsaiten mißlingen.

31. III. 1910. Der jedesmalige Versuch, Bougies einzuführen, mißlingt vollkommen und hat Pat. nachher hohe Temperaturen bis $40^{\circ}$ und daruber mit Pneumonie, wahrscheinlich hypostatischer Natur.

8. V. Operation fecit Prof. Hacker. Es wird erst mit dem Finger in die Fistel eingegangen und versucht die Kardia zu tasten. Dies gelingt; hierauf führt der Operateur eine Hohlbougie von der Fistel aus durch die Kardia und durch die Hohlbougie eine Darmsaite durch den Oesophagus, der sofort beim ersten Versuch durch den Mund herauskommt. Hierauf Anlegen eines Fadens ohne Ende. Die Operation wurde in Kelennarkose ausgeführt. Am ersten Tage keine Temperatursteigerung.

Zwischen 1. VI. und 30. VI. 1910 wurden die Magensekretionsversuche angestellt.

Krankengeschichte II.

Name: W. F.

Alter, Stand, Beruf: 59 J., verh. Kellerbursche.

Tag der Aufnahme: 7. V. 1920.

Abteilung: chirurg.

Diagnose: Stenosis oesophagi. 
Ausgang der Behandlung, Tag des Abganges: 26. VII. gestorben.

Anamnese: Vater an Asthma, Mutter an Lungentuberkulose gestorben.

7 Geschwister des Pat. leben, sind gesund. Pat. hat 2 gesunde Kinder.

War immer gesund bis zum jetzigen Leiden; dieses begann heuer zu Ostern. Damals trat zum erstenmal Würgen während der Mahlzeit auf, welches immer häufiger wurde. Es entstanden Schmerzen in der Magengegend, wenn die Bissen hinunterkamen. Konnte zuerst noch feste Speisen essen; seit 4 Tagen kann er aber auch keine Flüssigkeit mehr zu sich nehmen, alles kommt zurück und seit dieser Zeit ist Pat. auch sehr abgemagert. Sonst keine Beschwerden.

Status praesens: Mittelgroß, mittelkräftig, sehr mager, leicht kachekt. aussehend.

Temperatur, Puls: normal.

Abdomen: tief eingezogen (Kahnbauch), Därme kontrahiert, leer. Haut leicht in Falten abhebbar.

Herz, Lunge: ohne Befund.

In der linken Supraclaviculargrube am lateralen Kopfnickerrande eine haselnußgroße, derbe Virchowsche Drüse tastbar. Sonst am Halse keine Drüsen.

Pat. hat vor kurzem Wasser getrunken und würgt es jetzt wieder heraus.

Sternum ohne Dämpfung, kein Zeichen von Aneurysma.

7. V. Die Sondierung des Oesophagus ergibt: Zylinder-Bougie Nr. 12 stößt in $42 \mathrm{~cm}$ Entfernung von der Zahnreihe auf resistentes Hindernis. Bougie Nr. 2 läßt sich bis auf $32 \mathrm{~cm}$ vorschieben und ist bei dieser Tiefe deutlich fühlbar in der Stenose engagiert; weiteres Vorschieben in den Magen gelingt nicht. Bei $28 \mathrm{~cm}$ ein in die Speiseröhre von vorn links hineinragender, gelblich gefärbter Tumor von lappiger Gestalt, der das Lumen völlig verengt. Dort bleibt Sonde Nr. 2 engagiert. Wegen vollständiger Behinderung der Nahrungsaufnahme am

8. V. Operation in Lokalanästhesie fecit Dr. Bouvier.

Typische Gastrostomie nach v. Hacker.

Die Ernährung durch die Magenfistel gelingt anstandslos.

15. V. Entfernung der Nähte, Heilung p.p.

25. V. Die Durchgängigkeit des Oesophagus wird geprüft: Pat. schluckt Wasser (einige Kubikzentimeter) in Absätzen. Gleich darauf ganz leichtes Würgen und eine kleine Menge Flüssigkeit mit viel Schleim kommt zurück. Dies wiederholt sich (angeblich bei jeder Flüssigkeitsaufnahme) so lange, bis alles Getrunkene wieder regurgitiert ist. Am Schlusse des Regurgitierens kommt gewöhnlich etwas Blut mit, doch tritt kein Husten anf. Also: vollständige Unwegsamkeit des Oesophagus.

6. VII., 7. VII., 9. VII. Magensekretionsversuche. Das Allgemeinbefinden des Kranken ist ein verhältnismäßig gutes. Er hat keine Schmerzen, klagt nur über körperliche Schwäche und viel Durst. Läßt die Untersuchungen willig und ohne Angst über sich ergehen, da ihm gesagt wird, daß sie zwecks genauer Feststellung seines Leidens nötig seien.

26. VII. Unter zunehmender Kachexie Exitus.

Es handelte sich also in beiden Fällen um Kranke, welchen wegen totaler Oesophagusstriktur Magenfisteln angelegt waren. Daß die Oesophagusstrikturen zur Zeit der Versuche totale waren, erweist einmal der chirurgische Befund, dann aber die Untersuchung des während der Versuche aus der Fistel abgeflossenen Sekretes. Dasselbe wurde jedesmal auf das im Speichel konstant vorhandene Rhodankalium untersucht: die Probe fiel durchweg negativ aus, womit 
erwiesen erscheint, daß das abfließende Magensekret frei von. Speichelbeimengung, also während der Versuche niemals Speichel verschluckt worden war.

Die Versuche wurden in folgender Weise angestellt: In die Magenfistel wurde ein gut passendes Kautschukrohr (ein anderes als das zur künstlichen Ernährung verwendete) eingeführt, welches an mehreren Stellen seitliche Löcher trug; ein solches Loch war so angebracht, da $\dot{B}$ es unmittelbar innerhalb der Fistel, also an der Magenwand selbst lag. Über das äußere Ende des Schlauches wurde ein schief abgeschnittener Glasrohransatz gesteckt, um die Ausflußöffnung fixieren zu können. Die Versuchspersonen wurden so gelagert, daß die Magenfistel an den tiefsten Punkt des Magens zu liegen kam, der zuerst untersuchte Knabe auf den Bauch auf ein mit Öffnung versehenes Bett, die zweite Versuchsperson in linke Schräglage nach vorn. Der Glasansatz am Magenrohr wurde nun mittels einer an einem Stativ befestigten Klammer fixiert und so während eines ganzen Versuches am selben Punkte erhalten.

Zwecks genauer Feststellung der zeitlichen Verhältnisse der Magensekretion erschien es nötig, eine Methode zu verwenden, welche den Abfluß von Magensekret graphisch registrierte. Eine solche erschien in der von Nikolai beim Studium der Speichelsekretion verwendeten Apparatur gegeben. Die aus dem Magenrohr abfließende Flüssigkeitstropfen fielen zunächst aus einiger Höhe auf ein etwas schräg gestelltes Löffelchen, dessen Stiel den Hebel einer Mareyschen Trommel bildete; letztere war durch Schlauchleitung mit einem zweiten Mareyschen Tambour verbunden, dessen Hebel an der berußten Schleife des im Nebenzimmer aufgestellten Kymographions schrieb.

Infolge der Schrägstellung des Löffelchens floß jeder Tropfen, nach. dem er durch die Fallwirkung einen Ausschlag nach unten und damit einen solchen des Schreibhebels nach oben bewirkt hatte, rasch ab und wurde in einem untergestellten Maßzylinder aufgefangen. Die Elastizität der Gummimembran des Tambours bewirkte nun eine sofortige Einstellung des Löffels in der Ruhelage, so daß die Ausschläge für die einzelnen Tropfen annähernd gleich groß waren.

Am Kymographionstreifen wurde mittels eines Markiermagneten gleichzeitig mit der Registrierung der Sekrettropfen die Zeit in halben Sekunden geschrieben und jeweils die Reize zeitlich und nach ihrer Dauer markiert.

Da die Vermutung naheliegt, daß vasomotorische Einstellvorgänge die Magensekretion in hohem Maße mit beeinflussen dürften, so wurde bei der zweiten Versuchsperson eine mit der Registrierung der Magensekretion gleichzeitige Registrierung der vasomotorischen Veränderungen am (rechten) Arm mittels Plethysmographen vorgenommen. Leider mußte diese Versuchsreihe infolge äußerer Verhältnisse vor- 
zeitig abgebrochen werden, ergab aber immerhin trotz ihrer Kürze bemerkenswerte Resultate.

Die Versuche wurden an den Patienten in nüchternem Zustande (letzte Mahlzeit 5-15 Stunden vor Versuchsbeginn) vorgenommen.

Eine halbe bis ganze Stunde vor Beginn der Versuche wurde der Magen der Versuchsperson mit körperwarmem Wasser durch die Magenfistel ausgespült, bis das Spülwasser vollkommen rein abfloß.

Durch diese Versuchsanordnung war es ermöglicht, die Veränderungen der Magensekretion in ihren zeitlichen Verhältnissen genau zu überblicken; ferner gab sowohl die Tropfenzahl in der Zeiteinheit als auch das Verhältnis $\frac{\text { Sekretmenge }}{\text { Tropfenzahl }}$ während eines ganzen Versuches hinreichend genaue Aufschlüsse über die quantitativen Verhältnisse der Magensekretabscheidung.

Als Hauptfehlerquelle bei der Versuchsanordnung, die jedoch nicht zu umgehen war, ist zu berücksichtigen, daß zwischen der Abscheidung des Sekretes aus den Drüsen und dem Abfluß desselben aus dem Magenschlauch eine gewisse, sicher mehrere Sekunden lange Zeitspanne verfließen muß. Hierzu ist zu bemerken, daß diese Zeitspanne ceteris paribus eine ziemlich konstante Größe sein muß. Ferner war zu bemerken, daß trotz sorgfältigster Anbringung des Magenschlauches besonders hinsichtlich der Lage der ersten seitlichen Öffnung innerhalb des Magens (s. o.) ein restloser Abfluß des Sekretes niemals mit Sicherheit gewährleistet sein konnte, da die geringste Niveaudifferenz zwischen innerer Magenwand und Lücke im Schlauch bereits zur Ansammlung von etwas Sekret unterhalb der Schlauchlücke führen mußte, ein Fehler, der, wie sich zeigte, nicht mit Sicherheit vermieden werden konnte. Wenn sich jedoch einmal eine kleine Menge Sekretes angesammelt hatte, deren Spiegel gerade bis zur seitlichen Schlauchlücke reichte, so mußte dann der Zufluß jedes weiteren Sekrettropfens sofort den Abfluß eines gleich großen Tropfens durch den Magenschlauch verursachen.

Da sich bei Durchsicht der Versuchsresultate zeigte, daß die mittels der angewandten Methode meßbaren Veränderungen der Magensekretion innerhalb der registrierten Zeitintervalle von $1 / 2$ Sekunden zu gering waren, als daß man sie für die Beurteilung der Reizwirkung auf die Magensekretion verwerten könnte, so wurde die Tropfenzahl innerhalb der zwanzigfachen Zeit, also innerhalb 10 Sekunden, als Testwert für die Beurteilung der Magensekretionsveränderungen angenommen, was genügende Genauigkeit verbürgte.

Die Ergebnisse der Versuche habe ich in Tabellen und Kurven darzustellen versucht. In den Tabellen sind die Ergebnisse der Einzelreize übersichtlich dargestellt, und zwar der besseren Übersicht halber nach der Qualität der gesetzten Reize. 
Als Latenzzeit wurde in der ersten Versuchsreihe der Zeitabschnitt vom Beginn des Reizes bis zu einer deutlich nachweisbaren Veränderung des Magensaftabflusses angenommen. Dies erstens deshalb, weil der Eintritt des Reizes in das BewuBtsein mit der Setzung des Reizes zeitlich annähernd zusammentreffen mußte; zweitens, weil angenommen werden dürfte, daß mit der Apperzeption des Reizes auch jene Anteile des Zentralnervensystems in Funktion gesetzt werden, welche die sekretorische Tätigkeit der Magendrüsen regulativ beeinflussen.

Bei denjenigen Versuchen, in welchen eine Latenzzeit nicht sicher feststellbar war, weil eine deutliche Veränderung der Magensaftsekretion ausblieb, wurde die Zeit der Latenz mit $40^{\prime \prime}$ angenommen, was ungefähr dem Mittel der überhaupt festgestellten Latenzzeiten entspricht.

Die reaktive Magensaftsekretion wurde so dargestellt, daß zunächst die Zeit vom Fintritt der Reaktion bis zu deren Abklingen (Reaktionszeit) und ferner die Zahl der während dieser Zeit abgeflossenen Tropfen festgestellt wurde. Dort, wo eine Sekretionssteigerung ausblieb oder gar eine Abnahme der Sekretion auftrat, wurde die Reaktionszeit mit $100^{\prime \prime}$ angenommen, was nach dem Durchschnitte der Versuchsergebnisse reichlich zum Abklingen des Reizeffektes genügen mußte.

Zwecks besser möglicher Beurteilung der beobachteten Schwankungen des Sekretflusses wurde für den Gesamtversuch eines jeden Tages, in dessen Verlauf die einzelnen Reize gesetzt wurden, das Verhältnis $\frac{\text { Gesamtzahl der Sekrettropfen } \times 10}{\text { Gesamtzeit des Versuches in Sekunden }}$ berechnet. Der Quotient dieses Verhältnisses ergibt die durchschnittliche Magensaftsekretion in $10^{\prime \prime}$, welche während je eines Gesamtversuches in Erscheinung trat.

In den Tabellen wurde nun in der vierten Säule jene Tropfenzahl eingesetzt, welche nach der durchschnittlichen Sekretion des Tagesversuches in der ermittelten oder angenommenen Reaktionszeit zu erwarten gewesen wäre. Die in der fünften Säule der Tabellen eingetragene Differenz zwischen tatsächlich stattgehabter und durchschnittlicher Sekretion während der Reaktionszeit ermöglicht eine Beurteilung der Qualität und. Intensität der beobachteten Reaktionen.

Die Möglichkeit der Beurteilung der Reaktionen nach dieser errechneten Sekretionsdifferenz ist aber nicht für alle Fälle ausreichend. Denn häufig liefen die Reaktionen so ab, daß einer langsam einsetzenden und allmählich ansteigenden Sekretionsphase eine stürmische Phase rasch aufeinanderfolgenden Tropfenfalles folgte und weiterhin die Reaktion wieder allmählich abklang. Da doch alle drei derartigen 
Phasen zur Reaktion gerechnet werden müssen, ergab sich hieraus für die tabellenmäßige Darstellung der Fehler, daß die Differenz zwischen der reaktiven und der durchschnittlichen Sekretion vielfach kleiner erscheint, als der an der Originalkurve beobachteten Intensität der Reaktion entspricht. Dieser Fehler in der Darstellung ließ sich nur dadurch umgehen, daß der ganze Verlauf der Reaktion in Form von Kurven dargestellt wurde. Dies konnte aus äußeren Gründen der Drucklegung nur für einen Teil der Versuche geschehen, welche als Beispiele für die beobachteten Reaktionstypen gelten und im $\mathrm{Zu}$ sammenhalt mit den Tabellen eine Vorstellung über die tatsächlich beobachteten Verhältnisse vermitteln mögen.

Die Kurven sind so gezeichnet, daß als Abszisse die Zeit geteilt in Intervalle von je 10 Sekunden, als Ordinaten die Zahl der in diesen Zeitabschnitten aus dem Magenschlauch geflossenen und registrierten Tropfen eingetragen sind. Dadurch ergibt jede einzelne Kurve eine anschauliche Vorstellung über die während jedes Einzelversuches beobachteten Veränderungen der Magensaftsekretion.

Bei der Einzeichnung der Schwankungen des Armvolumens in die in Betracht kommenden Kurven kam es mehr darauf an, die Zeit und Qualität der Veränderung als ihre genaue Quantität darzustellen. Es wurde daher für die zeichnerische Darstellung eine Ordinateneinheit gewählt, welche $5 \mathrm{~mm}$ Ausschlag dos Schreibhebels der Mareyschen Trommel entspricht und dieselbe von der Ausgangsstellung des Hebels bei Versuchsbeginn (0) als positiver (Volumzunahme) oder negativer (Volumabnahme) Wert eingezeichnet. Auf die Berücksichtigung der Qualität der Einzelpulse wurde verzichtet, da aus den Volumveränderungen allein eine für die vorliegenden Fragen genügend genaue $\mathrm{Be}$ urteilung der vasovegetativen Einstellungsvorgänge ermöglicht erschien.

Art und Zeit der Reize wurden ebenfalls auf den Kurven verzeichnet; die an den Originalkurven genau ermittelten Latenzzeiten sind auf den gezeichneten Kurven eingetragen.

In sämtlichen Versuchen an beiden Versuchspersonen wurde ein dauerndes Abtropfen von Magensaft aus der Fistel beobachtet. Die einzelnen Tropfen flossen in Zeitintervallen ab, welche im Ruhezustande während längerer Zeitabschnitte im Laufe eines Tagesversuches untereinander ziemlich gleich waren. Auf Reize hin veränderten sich die Intervalle zwischen den einzelnen Tropfen, wurden kürzer oder länger, entsprechend einer Zunahme oder Abnahme der Magensaftsekretion. Da die Versuchspersonen nüchtern zu den Versuchen kamen, so erschien es zunächst nur noch möglich, daß der Reiz der Magenausspülung, welche vor jedem Tagesversuche vorgenommen wurde, den dauernden Magensaftfluß verursache, obwohl die Spülung mit körperwarmem 
Wasser durch die Magenfistel gewiß kein sehr differenter Reiz sein konnte. Es wurde daher die Zeit zwischen Magenausspülung und Versuchsbeginn bis zu einer Stunde verlängert. Trotzdem tropfte stets spontan und bei Vermeidung äußerer Reize Magensekret ab; diese Sekretion versiegte nicht einmal im Schlafe der Versuchsperson.

An verschiedenen Tagen war diese dauernde spontane Magensaftausscheidung verschieden stark, was als weiterer Beweis dafür aufgefaßt werden darf, daß sie inneren physiologischen Bedingungen und nicht äußeren Reizen ihre Entstehung verdankt.

Im folgenden sind zunächst die Ergebnisse der Versuche berichtet, welche an der Versuchsperson K. J. (Krankengeschichte 1) angestellt wurden.

\section{Physiologische Reize}

von der Schleimhaut der Mundhöhle aus.

Das Einbringen von Nahrungsmitteln in die Mundhöhle, der Kauakt und die Erregung der Geschmacksempfindung bilden zusammen einen Reizkomplex, welcher unter physiologischen Umständen die sezernierende Tätigkeit der Magendrüsen gesetzmäßig in Gang setzt (Pawlows Scheinfütterung u. a. m.). Es war daher zunächst festzustellen, ob bei der Versuchsperson dieser physiologische Mechanismus intakt funktionierte. Die Ergebnisse der bezüglichen Reizversuche sind in Tab. 1 zusammengestellt.

Tabelle 1.

\begin{tabular}{|c|c|c|c|c|c|c|c|}
\hline \multirow{2}{*}{ Reiz } & \multirow{2}{*}{ 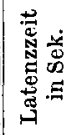 } & \multicolumn{2}{|c|}{ Sekretion } & \multirow{2}{*}{\begin{tabular}{|l} 
Durchschnittl. \\
Sekretion für \\
diese Zeit \\
Tropfen
\end{tabular}} & \multirow{2}{*}{$\begin{array}{c}\text { Differenz } \\
\text { Tropfen }\end{array}$} & \multirow{2}{*}{ Anmerkungen } & \multirow{2}{*}{$\begin{array}{l}\text { Kurven- } \\
\text { und Reiz } \\
\text { nummer }\end{array}$} \\
\hline & & in Sek. & Tropfen & & & & \\
\hline $\begin{array}{l}\text { 1. Kauen eines Stückes } \\
\text { Backwerkes, nachher } \\
\text { tusspucken desselben }\end{array}$ & 86,5 & 161 & 51 & 43,4 & $+7,6$ & & I, 7 \\
\hline 2. Hbenso & 43 & 75 & 12 & 8,9 & $+\mathbf{3}, 1$ & & II, 7 \\
\hline 3. Ébenso & 31 & 46 & 25 & 5,9 & $+19,1$ & & III, 13 \\
\hline 4. Ebenso & 100 & 142 & 65 & 18,4 & $+46,6$ & & III., 16 \\
\hline 5. Ebenso & 73 & 212 & 38 & 21,2 & $+18,8$ & & IV, 5 \\
\hline 6. Ebenso & 118 & 291 & 41 & 29,1 & $+10,9$ & & IV, 11 \\
\hline 7. Ebenso & 19 & 59 & 18 & 17,1 & $+0,9$ & $\begin{array}{l}\text { Wurde einige Minuten } \\
\text { vorher in die Wade } \\
\text { gestochen }\end{array}$ & $\mathrm{V}, 27$ \\
\hline $\begin{array}{l}\text { 8. Kaulu eines Bonbons, } \\
\text { nachher Ausspucken } \\
\text { desselben }\end{array}$ & 40 & 100 & 4 & 8 & -4 & $\begin{array}{l}\text { Latenz- und Reaktions- } \\
\text { zeit angenommen. Vp. } \\
\text { ist sehr schläfrig, in- } \\
\text { teresselos }\end{array}$ & $\mathrm{X}, 12$ \\
\hline
\end{tabular}


Ein Úberblick über Tab. 1 zeigt zunächst, daß die Latenzzeiten, welche vom Einbringen der Speisen in den Mund bis zum Auftreten einer Reaktion des Magensaftabflusses verstrichen sind, recht bedeutende Unterschiede zeigen. Wenn man von den beiden letzten Versuchen absieht, in denen ein besonderer steigernder Einfluß des Reizes auf die Magensaftsekretion überhaupt nicht erfolgte, so schwanken die Latenzzeiten zwischen 31 und 118 Sekunden. Der durchschnittliche Wert beträgt für die vorliegende Versuchsreihe ca. 75 Sekunden.

Auch die Reaktionszeiten, also jene Zeiten, während welcher eine Steigerung der Magensaftsekretion zu beobachten war, sind recht verschieden, zwischen 46 und 291 Sekunden. Dabei zeigt sich bei Vergleich der Reaktionszeiten mit den absoluten Zahlen der abgesonderten Sekrettropfen und den errechneten Differenzwerten gegenüber der durchschnittlichen Sekretion, daß durchaus kein proportionales Verhältnis zwischen Reaktionszeit und Sekretionsgröße besteht, so daß etwa immer dieselbe Sekretmenge in der Zeiteinheit abgeflossen wäre. Die Sekretion verlief das eine MaI stürmisch in kurzer Zeit, ein anderes Mal langsam in längerem Zeitintervall, auch lebhafte Sekretion durch lange Zeit konnte beobachtet werden, ebenso geringe Sekretionssteigerung, die rasch wieder abklang.

In den beiden letztangeführten Versuchen blieb das eine Mal eine nennenswerte Sekretionssteigerung aus, das andere Mal sank die Tropfenzahl sogar nach dem Reiz unter den durchschnittlichen Sekretionswert des Tagesversuches. Bei diesen beiden Versuchen bestand im Gegensatz zu den übrigen in dieser Tabelle angeführten das eine Mal Unlustaffekt, das andere Mal eine Veränderung des Gemeingefühles, während sich die Versuchsperson bei den übrigen Versuchen dieser Tabelle im physiologischen Wachzustande und im Stimmungsgleichgewicht befand.

Die im folgenden abgebildeten Kurven sollen den Sekretionsablauf nach physiologischen Reizen von der Mundhöhlenschleimhaut aus noch näher veranschaulichen.

Kurve 1. Nach einerLatenzzeit von $31^{\prime \prime}$ trat zunächst eine mäßige Sekretionssteigerung auf; auf dieselbe folgte eine geringe Sekretionsabnahme, und nun setzte erst lebhafter Magensaftfluß ein, welcher wieder sehr bald von einer Phase des Versiegens des Abflusses gefolgt war. Die Erschei-

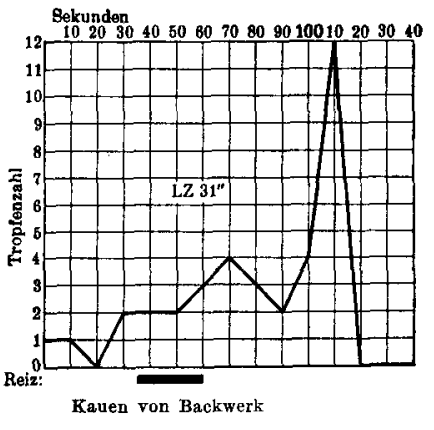

Kurve 1 (Versuch 1, Tabelle 1). nung, daß innerhalb einer Sekretionsphase solche Perioden von mehr oder weniger raschem An- und Abschwellen des Sekretabflusses ab- 
wechseln, wurde bei positiv ausgefallenen Reizversuchen fast durchgängig beobachtet und tritt an den bezüglichen Kurven deutlich zutage.

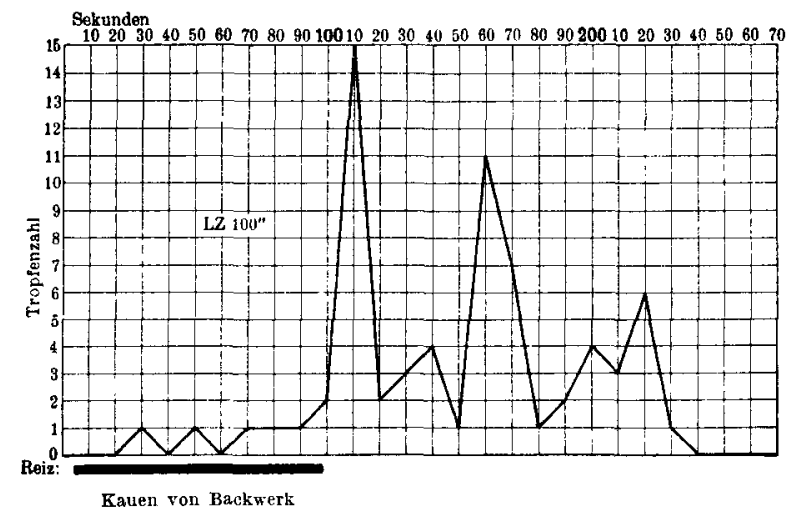

Kurve 2 (Versuch 4, Tabelle 1).

K u rve 2. In diesem Versuch ist nach Ablauf der Latenzperiode zunächst steiler Anstieg des Magensaftflusses zu beobachten, der rasch wieder absteigt. Zwei weitere Zacken der Kurve, jede niedriger als die vorige, zeigen die Periodizität des Sekretabflusses in diesem Versuche besonders deutlich.

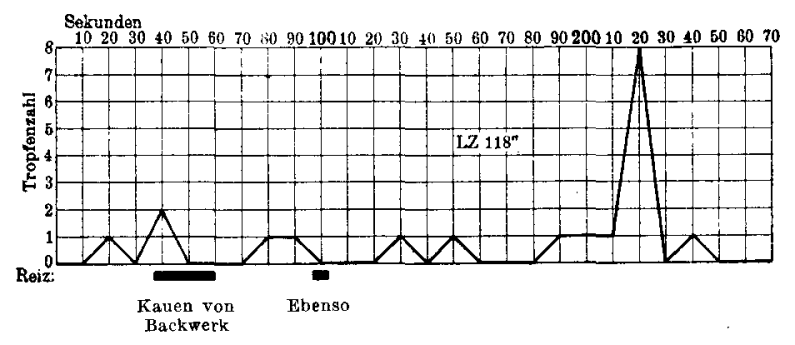

Kurve 3 (Versuch 5, Tabelle 1).

Kurve 3. Da es in diesem Versuche nach dem ersten Reiz innerhalb der vorauszusetzenden Zeit zu einem Sekretabfluß aus der Fistel nicht kam, wurde der Reiz wiederholt. Die Latenzzeit ist vom zweiten Reiz an gerechnet. Es waren bei diesem Versuche wohl Bedingungen vorhanden, welche den Sekretionsreflex hemmend beeinflußten. Darauf weist zunächst die Notwendigkeit der Reizwiederholung, dann die lange Latenzperiode und endlich der Umstand hin, daß nach der spät aufgetretenen Höchstreaktion keine Wiederholung lebhafteren Sekretflusses auftrat, sondern derselbe trüg und allmählich immer geringer ablief. Dieser zweite Teil der, Sekretion hat auf obiger Kurve nicht mehr Platz gefunden. 
$\mathrm{K}$ u r v e 4. Diese Kurve zeigt im Zusammenhalt mit der entsprechenden Notiz in der zugehörigen Tabelle, wie notwendig für die Beurteilung der reaktivenVeränderungen der Magensaftsekretion beides, sowohl Rechnung als auch Zeichnung, ist. Denn fast nur nach der Tatsache, daß eine positive Differenz gegenüber der durchschnittlichen Reaktion besteht, kann aus der sonst recht unansehnlichen Kurve eine Reaktion herausgelesen werden. Dabei ist

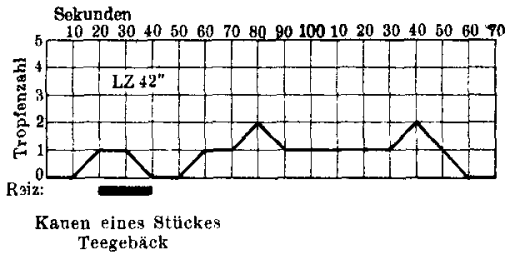

Kurve 4 (Versuch 2, Tabelle 1). auch bei der geringen Reaktion der Typus wiederholt eintretenden und wieder abflauenden Magensaftflusses erkennbar.

\section{Assoziationsreize im optischen Sinnesfeld.}

Vor allem fällt an den Versuchsergebnissen dieser Reihe auf, daß die Latenzzeiten durchschnittlich niedriger sind als nach den physiologischen Schleimhautreizen. Bei Berücksichtigung nur der sicher positiv ausgefallenen Versuche zeigt sich, daß die Latenzzeiten zwischen 31,5 und 64,5 Sekunden betragen; der Durchschnittswert ist 48 Sekunden, also wesentlich niedriger als der Durchschnitt der für die Schleimhautreize gefundenen Latenzzeiten.

Zweimal (Versuch 10, 17) wurden sehr kurze Latenzzeiten beobachtet, in beiden Fällen war die Reaktion sehr gering. Bei beiden Versuchen wurden Reize gesetzt, welche nächstverwandt waren zu anderen, im Verlaufe desselben Tagesversuches kurze Zeit vorher gesetzten Reizen. Es liegt nahe zu vermuten, daß die abnorm kurzen Latenzzeiten in diesen Fällen auf Reizkumulierung zurückzuführen sind.

Dagegen sind weder die absoluten Zahlen der in den Reaktionen abgeflossenen Tropfen noch die Differenzen zur durchschnittlichen Sekretion im Durchschnitte so hoch wie bei den physiologischen Schleimhautreizen.

Die Qualität der Reize hinsichtlich der Auswahl der optisch dargestellten Gegenstände oder Vorgänge weist einen deutlichen Einfluß auf die reaktive Magensaftsekretion auf, welcher sich besonders in den Differenzen zur durchschnittlichen Sekretion manifestiert (Reiz 1-6,9).

Ein proportionales Verhältnis zwischen Reaktionszeit und Sekretionsgröße ist auch in dieser Versuchsreihe nicht vorhanden.

Aus mehreren Versuchen dieser Reihe ist zu ersehen, daß auch nach assoziativen Reizen im optischen Sinnesfeld hemmende Wirkungen von Unlustaffekt und Veränderungen der Gemeingefühle auf die reaktive Magensaftsekretion festgestellt werden konnten (Versuch 8, $9,10,13,14$ ). 
Tabelle 2.

\begin{tabular}{|c|c|c|c|c|c|c|c|}
\hline \multirow{2}{*}{ Reiz } & \multirow{2}{*}{ 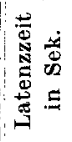 } & \multicolumn{2}{|c|}{ Sekretion } & \multirow{2}{*}{$\begin{array}{c}\text { Durchschnittl. } \\
\text { Sekretion für } \\
\text { diese Zeit: } \\
\text { Tropfen }\end{array}$} & \multirow{2}{*}{$\begin{array}{l}\text { Differenz: } \\
\text { Tropferı }\end{array}$} & \multirow{2}{*}{ Anmerkungen } & \multirow{2}{*}{$\begin{array}{l}\text { Kurven- } \\
\text { und Reiz- } \\
\text { nummer }\end{array}$} \\
\hline & & in Sek. & Tropfen & & & & \\
\hline $\begin{array}{l}\text { 1. Zeigen des Trichters, } \\
\text { welcher zur Fütte- } \\
\text { rung durch die Ma- } \\
\text { genfistel dient }\end{array}$ & 67,5 & 102 & 26 & 27,6 & $-1,6$ & & $\mathrm{I}, 1$ \\
\hline 2. Zeigen von Milch & 64 & 141 & 41 & 38 & +3 & & $\mathrm{I}, 2$ \\
\hline $\begin{array}{l}\text { 3. Zeigen eines Back- } \\
\text { werkes }\end{array}$ & 33 & 42 & 17 & 11,2 & $+5,8$ & & $\mathrm{I}, 3$ \\
\hline 4. Zeigen von Schinken & 64,5 & 152 & 31 & 18,3 & $+12,7$ & $\begin{array}{l}\text { Vp. gibt auf Befra- } \\
\text { gen an, daß er } \\
\text { Schinken sehr } \\
\text { gern ißt }\end{array}$ & II, 2 \\
\hline 5. Zeigen r. Backwerk & 61 & 85 & 16 & 10,2 & $+5,8$ & & II, 5 \\
\hline $\begin{array}{l}\text { 6. Zeigen des Fütte- } \\
\text { rungstrichters }\end{array}$ & 77 & 92 & 12 & 11 & +1 & & II, 6 \\
\hline $\begin{array}{l}\text { 7. Sieht ein durch den } \\
\text { Diener gebrachtes } \\
\text { Paket mit Backwerk }\end{array}$ & 57 & 96 & 18 & 12.4 & $+\tilde{b}, 6$ & & III, 11 \\
\hline $\begin{array}{l}\text { 8. Zeigen von Back- } \\
\text { werk }\end{array}$ & 27 & 73 & 6 & 7,3 & $-1,3$ & $\begin{array}{l}\text { Vp. ist mürrisch } \\
\text { und schläfrig }\end{array}$ & $\mathrm{IV}, 2$ \\
\hline $\begin{array}{l}\text { 9. Zeigen von } \mathrm{sch} \ddot{\mathrm{n}} \mathrm{n} \\
\text { gefärbtem Back- } \\
\text { werk }\end{array}$ & 44 & 140 & 68 & 40 & +28 & $\begin{array}{l}61^{\prime \prime} \text { nach Beginn } \\
\text { der Reaktion Stich } \\
\text { in dio Wade }\end{array}$ & $\mathrm{V}, 3$ \\
\hline $\begin{array}{l}\text { 10. Zeigen yon Back- } \\
\text { werk }\end{array}$ & 15 & 50 & 15 & 14,5 & $+0,5$ & $\begin{array}{l}\text { Vp. wurde in Ver- } \\
\text { lauf desselbenVer- } \\
\text { suches in dieWade } \\
\text { gestochen. Siehe } \\
\text { vorigen Reiz }\end{array}$ & $\mathrm{V}, 26$ \\
\hline $\begin{array}{l}\text { 11. Untersucher ißt ein } \\
\text { Bonbon, so daß } \mathrm{Vp} \text {. } \\
\text { dies sieht }\end{array}$ & 47,5 & 110 & 17 & 6,6 & $+10,4$ & $\begin{array}{l}\text { Vp. ist knapp vor } \\
\text { dem Reiz aus dem } \\
\text { Schlaf geweckt } \\
\text { worden }\end{array}$ & VIJ, 11 \\
\hline $\begin{array}{l}\text { 12. Zeigen von Bildern } \\
\text { von Obst. "Was } \\
\text { schmeckt Dir "hier- } \\
\text { von am besten?" Vp. } \\
\text { "Der Apfel!" }\end{array}$ & 31,5 & 72 & 15 & 4,3 & $+10,7$ & & VII, 15 \\
\hline $\begin{array}{l}\text { 13. Zeigen von Bildern } \\
\text { von Obst. Apfel und } \\
\text { Weintraube werden } \\
\text { benannt }\end{array}$ & 40 & 100 & 4 & : & -1 & $\begin{array}{l}\text { Latenz - und Reak- } \\
\text { tionszeit angenom- } \\
\text { men. Vp. hat vor } \\
\text { Beginn d.Versuche } \\
\text { angegeben, daß sie } \\
\text { heute Wund- } \\
\text { schmerzen habe }\end{array}$ & $\mathrm{IX}, 8$ \\
\hline
\end{tabular}


Tabelle 2. (Fortsetzung).

\begin{tabular}{|c|c|c|c|c|c|c|c|}
\hline \multirow{2}{*}{ Reiz } & \multirow{2}{*}{ 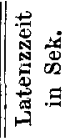 } & \multicolumn{2}{|c|}{ Sekretion } & \multirow{2}{*}{$\begin{array}{l}\text { Durchschnittl. } \\
\text { Sekretion für } \\
\text { diese Zeit: } \\
\text { Tropfen }\end{array}$} & \multirow{2}{*}{$\begin{array}{l}\text { Differenz: } \\
\text { Tropfen }\end{array}$} & \multirow{2}{*}{ Anmerkungen } & \multirow{2}{*}{$\begin{array}{l}\text { Kurven- } \\
\text { und Reiz } \\
\text { nummer }\end{array}$} \\
\hline & & in Sek. & Tropfen & & & & \\
\hline $\begin{array}{l}\text { 14. Zeigen eines schön } \\
\text { gefärbten Bonbons. } \\
\text { Euphor. Mimik. der } \\
\text { Vp. }\end{array}$ & 40 & 100 & 1 & 5 & -4 & Wie in Versuch 13 & $\mathrm{IX}, 11$ \\
\hline $\begin{array}{l}\text { 15. Zeigen eines Bildes } \\
\text { von Obst. "Was ist } \\
\text { das? Vp. "Wein- } \\
\text { traube!" }\end{array}$ & 34 & 117 & 14 & 9,3 & $+4,7$ & ! & $X, 5$ \\
\hline 16. Zeigen v. Backwerk & 50 & 68 & 9 & 4,7 & $+4,3$ & & XII, 9 \\
\hline $\begin{array}{l}\text { 17. Untersucher ißt } \\
\text { Backwerk, so daß } \\
\text { Vp. dies sieht }\end{array}$ & 14 & 74 & 7 & 5,1 & $+1,9$ & & XII, 12 \\
\hline
\end{tabular}

Die nun folgenden Kurven zeigen deutlich den Einfluß der Reizqualität auf den reaktiven Magensaftfluß.

Kurve 5. Der optische Eindruck von Backwerk allein genügte, um nach kurzer Latenzzeit einen typischen Magensaftflu $\beta$ hervorzurufen. So wie bei vielen anderen positiven Versuchen trat zunächst stürmischer Tropfenabfluß in Erscheinung, der rasch abklang und von einer Phase trägerer Sekretion gefolgt war.

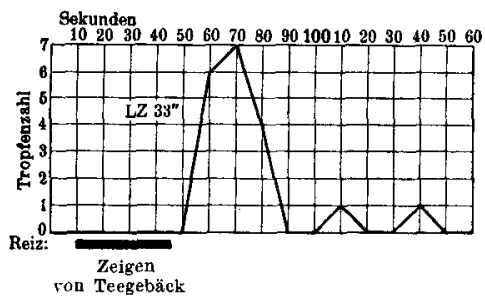

Kurve 5 (Versuch 8 , Tabelle 2).

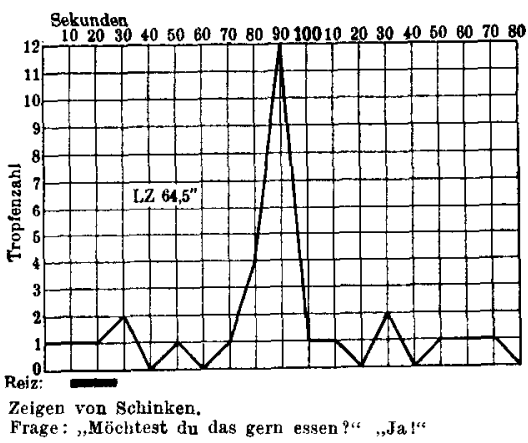

Kurve 6 (Versuch 4, Tabelle 2).

K u rve 6. Gegenüber dem vorher abgebildeten Reizerfolg ist hier die Latenzzeit verlängert; die initiale Sekretionszacke der Kurve ist jedoch wesentlich höher als im vorigen Versuche. Ferner sehen wir auch in der weiteren Phase des trägeren Saftflusses höhere Werte als in der vorigen Kurve. Ein Vergleich beider Kurven ergibt, daß der Magensaftfluß, welcher auf den optischen Eindruck ,Fleisch“ erfolgte, größer war und lebhafter verlief als derjenige, welcher auf den optischen Eindruck „Backwerk“ hin erfolgte. 
Kurve 7. Der Einfluß der Reizqualität auf den Magensaftfluß erscheint hier bei Vergleich mit Kurve 6 noch deutlicher und deshalb besonders

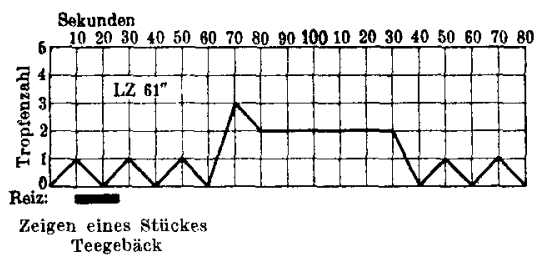

Kurve 7 (Versuch 5, Tabelle 2). lehrreich, weil die beiden Reize im Verlaufe eines Tagesversuches, also unter annähernd denselben inneren Bedingungen der Versuchsperson erfolgten.

Auf den optischen Eindruck „Backwerk" erscheint nach annähernd gleicher Latenzzeit wie nach dem optischen Eindruck „Fleisch" gesteigerter Magensaftfluß. Derselbe bleibt aber sowohl nach Intensität als auch nach Extensität weit hinter dem in Kurve 6 verzeichneten zurück. (Vgl. auch Tabelle.) Eine initiale Sekretionszacke erscheint nur angedeutet, die ganze Sekretion erfolgt gegenüber der auf „Fleisch" eingetretenen träge und weniger ausgiebig.

K u r v e 8. DieserVersuch ist ein Beispiel dafür, daß nicht nur der räumlich-optische Eindruck von tatsächlich vorhandenen appetitanregenden

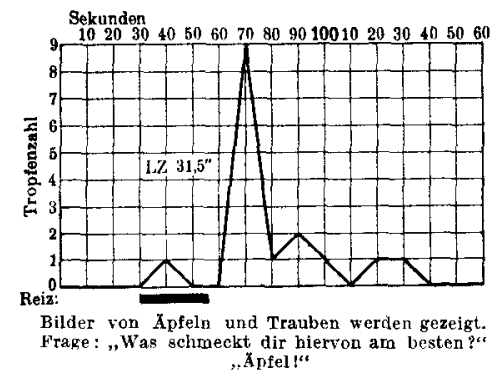

Kurve 8 (Versuch 12, Tabelle 2). Nahrungsmitteln imstande ist, Magensaftfluß anzuregen, sondern daß auch die an das bildliche Symbol von Nahrungsmitteln allein geknüpften Assoziationen genügen, um als Reiz auf den Sekretionsmechanismus zu wirken. Die Latenzzeit ist kurz, die initiale Sekretionszacke steil und hoch. Der Magensaftabfluß verläuft weiterhin in typischer Weise allmählich träger und mit geringeren Schwankungen. Die gesamte Reaktion verlief also im ganzen analog wie die auf den optischen Eindruck wirklich vorhandener eßbarer Gegenstände.

In K urve 9 ist zunächst die mächtige reaktive Magensaftsekretion bemerkbar, welche nach mittlerer Latenzzeit auf den optischen Reiz hin einsetzte. Mangels anderer Kenntnisse über veränderte Bedingungen des Reizerfolges und bei dem Umstande, als die Versuchsperson im selben Tagesversuche angegeben hatte, sie sei nicht hungrig (s. Versuch 7, Tab. 3) kann die Intensität und Extensität der Reaktion vielleicht auf die Reizqualität (besonders schöne Färbung des Backwerkes?) bezogen werden.

Der Ablauf des Magensaftflusses ist im ganzen typisch; wir sehen eine initiale Sekretionszacke mit raschem Abstieg, darauf folgende niedrigere, in diesem Falle übrigens noch immer beachtenswert hohe und steile Zacken. 
Während des Ablaufes der Reaktion wurden zwei unlustbetonte Reize gesetzt. Beide hatten eine starke Abnahme des Saftflusses zur Folge, welche besonders dadurch als Reizerfolg charakterisiert ist, daß

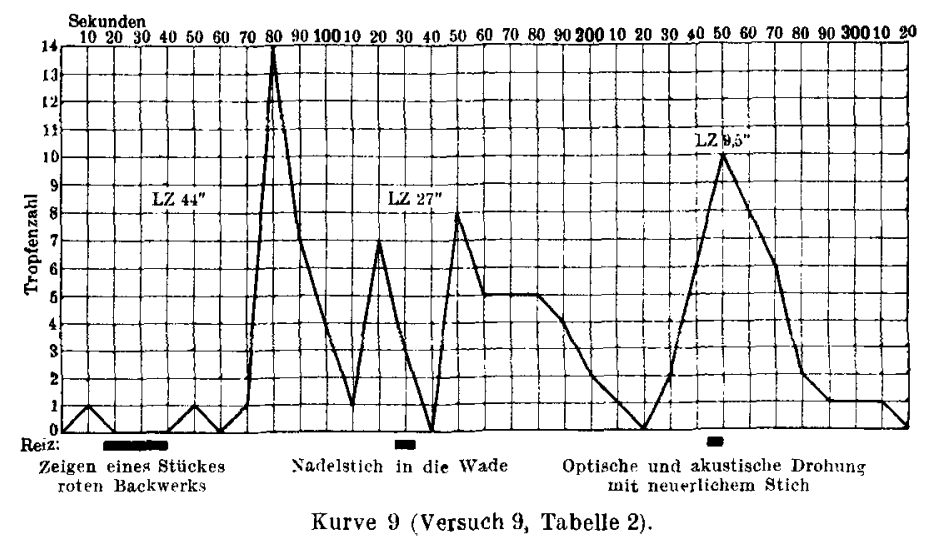

der Typus der Saftabsonderung sich auf die Reize hin ändert. Die Sekretionszacken rücken weiter auseinander, ihre absteigenden Schenkel werden länger. Man gewinnt beim Studium der Kurve den Eindruck, daß die Interpolation der unlustbetonten Reize das weitere phasische Auftreten von Sekretionszacken gehemmt hat und daß nun diese nicht voll in Erscheinung getretenen Sekretionssteigerungen den sonst steilen Abstieg der noch vorhandenen Sekretionszacken verflacht haben.

\section{Assoziationsreize im akustischen Sinnesfeld.}

Wie aus Tab. 3 ersichtlich, sind die Latenzzeiten nach Assoziationsreizen im akustischen Sinnesfeld im Durchschnitt noch kürzer, als nach solchen im optischen. Wenn nur die sicher positiven Versuche berücksichtigt und abnorm kurz erscheinende Reaktionszeiten zunächst von der Betrachtung ausgeschaltet werden, so findet sich die Größe der Latenzzeiten noch immer zwischen 15 und 55,5 Sekunden; der Durchschnitt beträgt 29 Sekunden.

Die abnorm kurzen Latenzzeiten in Versuch 5, 11, 14 dürften vielleicht nach derselben Utberlegung, welche oben für die gleiche Erscheinung nach optischen Reizen angestellt wurde, auf Reizkumulierung bezogen werden. $\mathrm{Ob}$ die geringe Latenzzeit in Versuch 3 auf einen inneren Bereitschaftszustand der Versuchsperson zurückzuführen ist und dadurch ebenfalls eine Art von Reizkumulierung vorliegt, kann infolge der vereinzelten Beobachtung nur vermutet werden.

Die absoluten Zahlen der abgeflossenen Tropfen sowohl als auch die Differenzen zur durchschnittlichen Reaktion sind nach akustischen Reizen im Durchschnitte wesentlich höher gefunden worden als nach 
Tabelle 3.

\begin{tabular}{|c|c|c|c|c|c|c|c|}
\hline \multirow{2}{*}{ Reiz } & \multirow{2}{*}{ 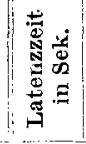 } & \multicolumn{2}{|c|}{ Sekretion } & \multirow{2}{*}{$\begin{array}{c}\text { Durchschnittl. } \\
\text { Sekretion für } \\
\text { diese Zeit: } \\
\text { Tropfen }\end{array}$} & \multirow{2}{*}{$\begin{array}{l}\text { Difierenz: } \\
\text { Tropfen }\end{array}$} & \multirow{2}{*}{ Anmerkungen } & \multirow{2}{*}{$\begin{array}{l}\text { Kurven- } \\
\text { und Reiz- } \\
\text { nummer }\end{array}$} \\
\hline & & in Sek. & Tropfen & & & & \\
\hline $\begin{array}{l}\text { 1. Aufforderung, frü- } \\
\text { her gezeigtes Back- } \\
\text { werk zu kosten }\end{array}$ & 15 & 137 & 69 & 37 & +32 & & $I, 4$ \\
\hline $\begin{array}{l}\text { 2. „Bist du hungrig? } \\
\text { Möchtest du etwas } \\
\text { essen } ?^{t 4}\end{array}$ & 29 & 89 & 42 & 10,7 & $+31,3$ & & II, 1 \\
\hline $\begin{array}{l}\text { 3. „Bist du hungrig? } \\
\text { Wie lange hast du } \\
\text { nichts zu essen ge- } \\
\text { habt? }\end{array}$ & 6 & 71 & 35 & 9,2 & $+25,8$ & & III, 1 \\
\hline $\begin{array}{l}\text { 4. Befehl an Hilfsper- } \\
\text { son: "Holensie Back- } \\
\text { werk!" }\end{array}$ & 38 & 85 & 28 & 11 & +17 & & III, 4 \\
\hline $\begin{array}{l}\text { 5. "Hast du grehört, daß } \\
\text { Backwerk geholt } \\
\text { wird? Freust du dich } \\
\text { darauf?" Vp.: „Ja!"* }\end{array}$ & 8,5 & 45 & 11 & 5,8 & $+5,2$ & $\begin{array}{l}\text { Reiz wurde inl An- } \\
\text { schluß an die bei- } \\
\text { den obigen ge- } \\
\text { setzt. }\end{array}$ & III, 5 \\
\hline $\begin{array}{l}\text { 6. "Was würde dir } \\
\text { große Freude ma- } \\
\text { chen?" Tp.: "Back- } \\
\text { werk!" }\end{array}$ & 14 & 47 & 27 & 6,1 & $+20,9$ & & III. 8 \\
\hline $\begin{array}{l}\text { 7. „Bist du hungrig? } \\
\text { Vp.: ,Nein!" }\end{array}$ & 55,5 & 110 & 43 & 31,9 & $+7,1$ & & $V, 10$ \\
\hline $\begin{array}{l}\text { 8. "Glaubst du, daß } \\
\text { Backerei da ist.?" } \\
\text { Vp.: ,Ja!" }\end{array}$ & 24,5 & 66 & 5 & 19,1 & $-14,1$ & $\begin{array}{l}\text { Vp. ist nicht hungrig } \\
\text { (s. vorigen Reiz). } \\
\text { Während des Se- } \\
\text { kretionsbeginnes } \\
\text { wurde an die Tür } \\
\text { geklopft, dieselbe } \\
\text { mußte geöffnet n. } \\
\text { durch sie gespro- } \\
\text { chen werden }\end{array}$ & $\mathrm{V}, 1$ \\
\hline 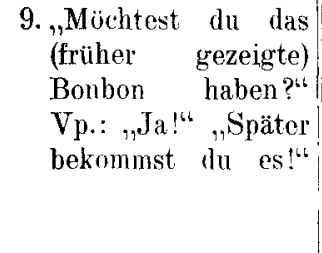 & 40 & 100 & 3 & 5 & -2 & $\begin{array}{l}\text { Latenz- und Reak- } \\
\text { tionszeit angenom- } \\
\text { men. Vp. hat vor } \\
\text { Beginn der Ver- } \\
\text { suche angegeben, } \\
\text { daß sie Wund- } \\
\text { schmerzen habe }\end{array}$ & IX, 12 \\
\hline $\begin{array}{l}\text { 10. "War das (frïher ge- } \\
\text { kaute) Bonbon sehr } \\
\text { gut?"? Vp.: "Ja!" }\end{array}$ & 40 & 100 & 6 & 8 & -2 & $\begin{array}{l}\text { Latenz- und Reak- } \\
\text { tionszeit angenom- } \\
\text { men. Vp. ist sehr } \\
\text { schläfrig, inter- } \\
\text { esselos }\end{array}$ & $\mathrm{x}, 14$ \\
\hline
\end{tabular}


Tabelle 3 (Fortsetzung).

\begin{tabular}{|c|c|c|c|c|c|c|c|}
\hline \multirow{2}{*}{$\operatorname{R} \in \dot{1 z}$} & \multirow{2}{*}{ 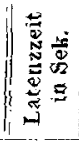 } & \multicolumn{2}{|c|}{ Sekretion } & \multirow{2}{*}{$\begin{array}{l}\text { Durchschnitt]. } \\
\text { Sekretioni fur } \\
\text { diese Zeit: } \\
\text { Tropter }\end{array}$} & \multirow{2}{*}{$\begin{array}{l}\text { Dijserenz: } \\
\text { Tropten }\end{array}$} & \multirow{2}{*}{ Anmerkungen } & \multirow{2}{*}{$\begin{array}{l}\text { Rurven- } \\
\text { und Reiz } \\
\text { nummonez }\end{array}$} \\
\hline & & in Sek. & Tropfen & & & & \\
\hline $\begin{array}{l}\text { 11. Rascheln mit Seiden- } \\
\text { papier: in solches } \\
\text { war gewöhulich } \\
\text { Backwerk einge- } \\
\text { wickelt. }\end{array}$ & 5 & 58 & 10 & 4 & +6 & $\begin{array}{l}\text { Reizwiederholung. } \\
\text { Gleicher Reiz } \\
\text { wurde knapp vor- } \\
\text { her unabsichtlich } \\
\text { gesetzt und führte } \\
\text { z. analogem Effekt }\end{array}$ & $\mathrm{X}[\mathrm{I}, \mathrm{8}$ \\
\hline 12. Ebenso & 42 & 56 & 7 & 3,9 & $+3,1$ & & XII, 15 \\
\hline 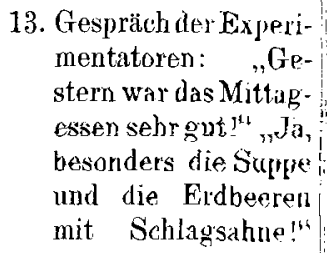 & 37,5 & 52 & 9 & 3,6 & $+5,4$ & & $\begin{array}{c}\text { XII, } \\
20-28\end{array}$ \\
\hline 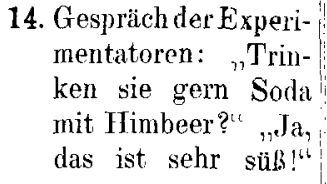 & 6 & 45 & 11 & 3,1 & $+7,9$ & $\begin{array}{l}\text { Unuittelbar nach } \\
\text { dem obenstehen- } \\
\text { den Reiz }\end{array}$ & $\begin{array}{c}\mathrm{XII} \\
24-25\end{array}$ \\
\hline $\begin{array}{l}\text { 15. Rascheln mit Seiden- } \\
\text { papier. }\end{array}$ & $20, \overline{5}$ & 67 & 8 & 5,3 & $+2,7$ & $\begin{array}{l}\text { Vp. ist sehr schläf- } \\
\text { rig, nahe am Ein- } \\
\text { schlafen }\end{array}$ & $\mathrm{XIV}, 2$ \\
\hline $\begin{array}{l}\text { 16. Möuhtest du ein seler } \\
\text { gutes Bonbon? ?" } V_{\mathrm{p} .} \\
\text { "Ja!" }{ }_{19} \mathrm{Du} \text { darfst } \\
\text { aber nicht schlafeu, } \\
\text { dann bekommst du } \\
\text { es!" }\end{array}$ & 40 & 100 & 1 & 8 & -7 & $\begin{array}{l}\text { Latenz- und Reak- } \\
\text { tionszeitangenom- } \\
\text { men. Vp. ist sehr } \\
\text { schläfrig, nahe am } \\
\text { Einschlafen }\end{array}$ & XIV, 4 \\
\hline $\begin{array}{l}\text { 17. Rascheln mit Seiden- } \\
\text { papiel. }\end{array}$ & 22 & 210 & 80 & 16,8 & $+63,2$ & $\begin{array}{l}\text { Vp. ist nun im Ge- } \\
\text { gensatz zu den bei- } \\
\text { den vorigen Rei- } \\
\text { zen wieder voll- } \\
\text { kommen wach, } \\
\text { spontan aufnerk- } \\
\text { sam }\end{array}$ & $\mathrm{XIV}, 5$ \\
\hline
\end{tabular}

optischen Reizen und erreichen nicht nur, sondern ubersteigen sogar vielfach die nach Kaureizen gefundenen Werte.

Ebensowenig wie in den beiden vorigen Versuchsreihen konnte für akustische Reize ein proportionales Verhältnis zwischen Reaktionszeit und Sekretionsgröße gefunden werden.

Ein Einfluß der Reizqualität, welche für diese Art Reize ja natür- 
lich viel schwerer feststellbar ist als für optische, auf die Sekretions. größe konnte nicht festgestellt werden.

Von besonderem Interesse erscheinen die Versuche 11, 12, 15, 17, da bei ihnen ein ohne willkürliches Zutun des Untersuchers entstandener „bedingter Reflex" zutage tritt.

In den Versuchen $8,9,10,15,16$ ist der hemmende Einfluß von Unlustaffekten und Veränderungen der Gemeingefühle auf die Magensaftsekretion auch nach Assoziationsreizen im akustischen Sinnesfeld

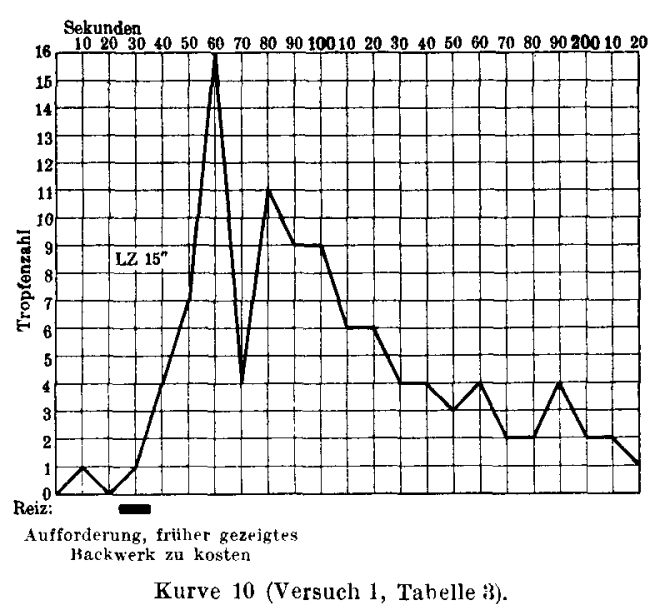
deutlich ersichtlich.

Die nun folgenden Kurven sind beispielsweise graphische Darstellungen von Versuchen aus Tab. 3.

K u rve 10. Der akustische Reiz löste nach sehr kurzer Latenzzeit stürmischen und ausgiebigen Magensaftabfluß aus. Wie bei den meisten Versuchen, ist. auch hier eine initiale Sekretionszacke und ein darauffolgendes phasenartig wechselndes Ansteigen und $\mathrm{Ab}$ schwellen des Magensaftflusses deutlich ausgeprägt, welches allmählich immer geringere Ausschläge zeigt, je länger die Reaktion dauert.

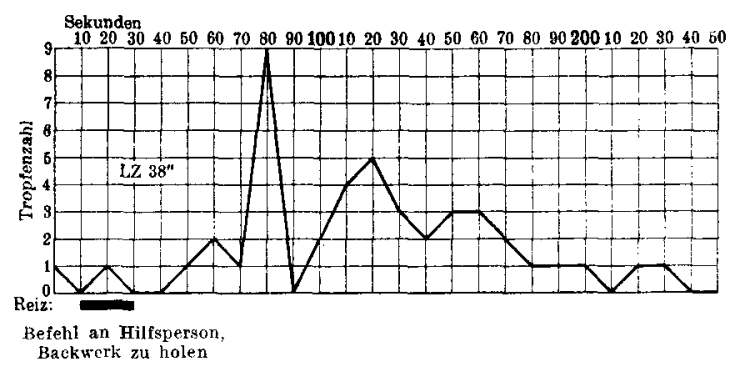

Kurve 11 (Versuch 4, Tabelle 3 ).

K urve Il. Aus diesem und analogen Versuchen geht hervor, daß ein akustischer Assoziationsreiz durchaus nicht nur dann Erregung der Magensaftsekretion zur Folge hat, wenn er in einer direkten Aufforderung zur Nahrungsaufnahme besteht. In diesem Falle genügte die Aufforderung, Backwerk, also appetiterregende Nahrungsmittel, herbeizubringen an eine dritte Person, um den Magensaftflu $B$ zu steigern. Auch hier zeigt sich phasenartiger Ablauf des Magensaftflusses, wobei bemerkenswert 
ist, daß hier auch der Anstieg des Sekretflusses sich analog wie der Abstieg verhielt, nämlich phasische Stufen zeigte.

Kurve 12. Die experimentell auf akustischem Wege hervorgerufene Assoziation ,Backwerk" löste nach kurzer Latenzzeit deutliche, wenn auch nicht sehr intensive Steigerung des Magensaftflusses aus; das phasische Abklingen dieser Reaktion ist gut erkennbar.

Da nach Ablauf dieser Reaktion ohne neuerlichen äußeren Reiz unvermittelt neuerlich Steigerung des Magensaftflusses auftrat, wurde die Versuchsperson gefragt, an was sie gedacht habe, da die Vermutung

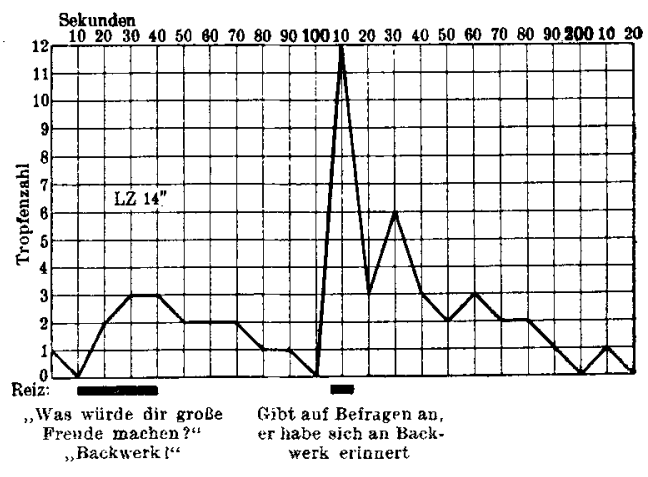

Kurve 12 (Versuch 6, Tabelle 3). nahelag, daß eine spontane Assoziation zur reaktiven Sekretion von Magensaft geführt habe. Tatsächlich bewies die Antwort, daß sich die erste Assoziation wiederholt und nun viel lebhafteren Magensaftfluß als das erstemal hervorgerufen hatte, welcher mit initialer Sekretionszacke und phasischem Abklingen in typischer Weise verlief. Der größere Effekt der zweiten, spontanen Assoziation ist vielleicht auf kumulative Reizwirkung zweier aufeinanderfolgender gleichartiger Assoziationen zu beziehen.

Außer dieser und der nächsten Kurve sowie Versuch 7, Tab. 3, geht hervor, daß nicht nur die konkrete Vorstellung von Nahrungsmitteln, welche durch einen entsprechenden akustischen Reiz hervorgerufen wird, imstande ist, die Magensekretion anzuregen, sondern daß schon die ebenso erregte abstrakte Vorstellung „Hunger" und die unbestimmte ,Essen" allein hiezu genügen, und zwar scheinbar selbst dann, wenn das entsprechende Gemeingefühl beim Individuum nicht vorhanden ist (Versuch 7, Tab. 3). In letzterem Falle war die Reaktion ebenfalls deutlich, aber geringer als wenn die Versuchsperson das Vorhandensein von Hungergefühl zugab.

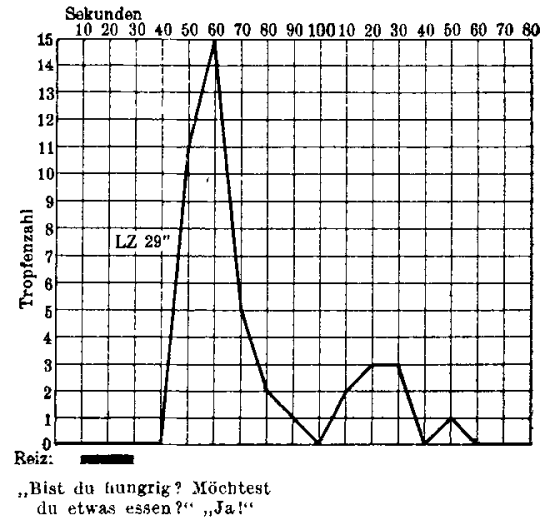

Kurve 13 (Versuch 2, Tabelle 3).

Kurve 13. In vorliegendem Versuche löste die akustisch hervorgerufene Assoziation ,Hunger" und ,Essen" mächtige und stürmisch ver- 
laufende Saftabsonderung aus, bei welcher die initiale Sekretionszacke sehr hoch, die folgenden phasischen Sekretionsschwankungen niedrig und vielleicht etwas verzögert erscheinen. Allerdings ist die zeitliche Ausdehnung der initialen Zacke hier besonders groß.

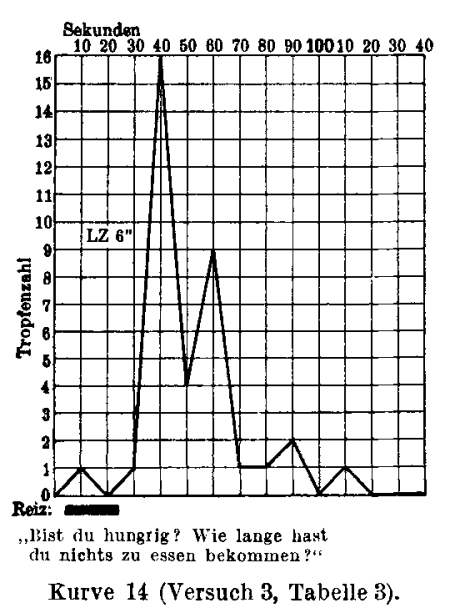

Kurve 15. Dieselben akustisch hervorgerufenen Assoziationen führten hier zum analogen Effekt auf die Magensaftsekretion wie in Kurve 13. Auffallend ist hier die abnorm kurze Reaktionszeit, welche, wie schon oben gesagt, vielleicht auf eine besondere innere Bereitschaft der Ver. suchsperson, d. h. auf tatsächlich vorhandenes starkes Hungergefühl zurückzuführen sein dürfte.

Die Magensaftabsonderung verlief ganz typisch mit initialer Sekretionszacke und phasischem Abklingen.

K u r ve 15 zeigt als Beispiel den mächtigen Einfluß eines reinen ,,bedingten Reflexes", welcher im Verlauf der Versuche ohne Absicht des Untersuchers entstanden ist, auf die Magensaftsekretion.

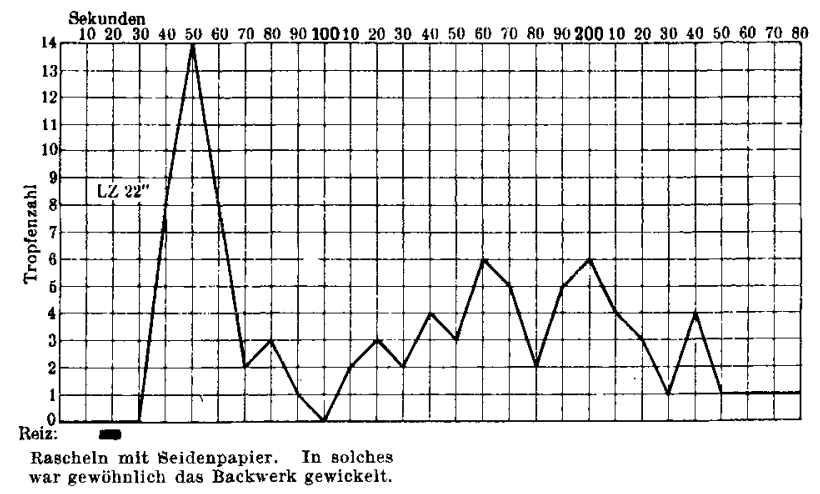

Kurve 15 (Versuch 17, Tabelle 3).

Nach kurzer Latenzzeit erscheint eine hohe und zeitlich ausgedehnte initiale Sekretionszacke; sie ist gefolgt von weiteren phasisch auftretenden Sekretionssteigerungen, welche zunächst in ihrer Gesamtheit sogar neuerliche, langsame Zunahme, erst weiterhin langsame Abnahme des Saftflusses erweisen.

Von weiterem Interesse ist dieser Versuch deshalb, weil er im Zusammenhalte mit Versuch 16, Tab. 3, den Einfluß der Gemeingefühle und der Gesamteinstellung der Versuchsperson auf den reaktiven Effekt 
von Reizen auf die Magensaftsekretion erweist. Während der Reiz in Versuch 16 bei dem fast schlafenden Versuchsindividuum zu keinem Saftfluß, gegenüber der durchschnittlichen Reaktion sogar zu einem negativen Effekt führte, stellte sich gleich nachher, als die Versuchsperson wieder vollkommen munter und auf die Vorgänge in der Umgebung aufmerksam war, unter dem Einfluß des bedingten Reflexes eine mächtige reaktive Magensaftsekretion ein.

Mehrere Versuche aus den bisher mitgeteilten Versuchsreihen zeigten in Übereinstimmung mit den aus der Literatur bekannten Tatsachen, daß Unlustaffekten, sowie gewissen Veränderungen der Gemeingefühle ein hemmender Einfluß auf die Magensaftabsonderung zukam.

Es wurden deshalb zunächst eine Reihe von Versuchen angestellt, um den Einfluß von Affekten auf die Magensekretion mittels absichtlich gesetzter entsprechender Reize genauer zu studieren. Die Ergebnisse dieser Versuche sind in Tab. 4 und 5 und den entsprechenden Kurven dargestellt.

\section{Unlustaffekt.}

Ein Überblick über Tab. 4 zeigt, daß in 6 von 7 Versuchen die Differenz zwischen reaktiver Magensaftsekretion nach unlustbetonten Reizen und durchschnittlicher Sekretion des Tagesversuches eine negative Größe war, die einige Male sogar beträchtliche Werte erreichte. Weiterhin sind für die Beurteilung des Einflusses von Unlustaffekt auf die Magensaftsekretion noch Versuch 7, Tab. 1, die Versuche 10, 13, 14, Tab. 2, und Versuch 9 Tab. 3 mit in Betracht zu ziehen. In allen diesen Versuchen zeigte sich eine Verringerung oder Abnahme des Magensaftflusses unter dem Einflusse unlustbetonter Reize, sei es, daß ein solcher Reiz dauernd bestand (Wundschmerzen), sei es, daß er experimentell gesetzt wurde.

Die Feststellung der Latenzzeit nach unlustbetonten Reizen war nur in vier Versuchen (Versuch 1, 3, 6, 7, Tab. 4) möglich, weshalb ein abschließendes Urteil darüber nicht abgegeben werden kann. Aus den vier Versuchen, in welchen die Feststellung möglich war, scheint hervorzugehen, da $\beta$ die Latenzzeit, welche zwischen unlustbetontem Reiz und hemmendem Effekt auf die Magensaftsekretion verstreicht, sehr kurz ist (Maximum $36^{\prime \prime}$, Minimum $9^{\prime \prime}$ ).

Dauernde Einstellung im Sinne eines Unlustaffektes vermag nach den bezüglichen Versuchen, besonders der Tab. 1-3, die Magensaftsekretion offenbar dauernd in dem Sinne zu beeinflussen, daß der unter sonstigen Umständen erfolgende sekretionssteigernde Effekt entsprechender Reize abgeschwächt oder unterdrückt wird. Dies entspricht ja auch den Beobachtungen Bickels u. a. 
II. Schrottenbach :

Tabelle 4.

\begin{tabular}{|c|c|c|c|c|c|c|c|}
\hline \multirow{2}{*}{ Reiz } & \multirow{2}{*}{ 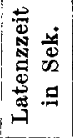 } & \multicolumn{2}{|c|}{ Sekretion } & \multirow{2}{*}{\begin{tabular}{|c|} 
Durchschnittl. \\
Sekretion fur \\
diese Zeit \\
Tropfen
\end{tabular}} & \multirow{2}{*}{$\begin{array}{l}\text { Differenz } \\
\text { Tropfen }\end{array}$} & \multirow{2}{*}{ Anmerkungen } & \multirow{2}{*}{$\begin{array}{l}\text { Kurven- } \\
\text { und Reiz- } \\
\text { nummer }\end{array}$} \\
\hline & & in Sek. & Tropfen & & & & \\
\hline $\begin{array}{l}\text { 1. Der Vp. wird Milch } \\
\text { gezeigt. Gleichzeitig } \\
\text { energisches Verbot: } \\
\text { "Du darfst sie aber } \\
\text { nicht trinken!" }\end{array}$ & 36 & 87 & 8 & 10,4 & $-2,4$ & & II, 11 \\
\hline $\begin{array}{l}\text { 2. Drohung, Vp. muisse } \\
\text { das ihr geschenkte } \\
\text { Spielzeug wieder her- } \\
\text { geben. Keine Ver- } \\
\text { änderung der Mimik } \\
\text { der Vp. }\end{array}$ & 40 & 100 & 30 & 29 & +1 & $\begin{array}{l}\text { Latenz- und Reak- } \\
\text { tionszeit ange- } \\
\text { nommen }\end{array}$ & $V, 14$ \\
\hline 3. Stich in die Wade & 13 & 57 & 11 & 16,5 & $-5,5$ & & $\mathrm{~V}, 28$ \\
\hline $\begin{array}{l}\text { 4. Zeigen eines Stückes } \\
\text { Backwerk, dasVp.ver- } \\
\text { langt. Gleichzeitig } \\
\text { wird } V_{p} \text {. aufmerksam } \\
\text { gemacht, daß sie fast } \\
\text { aus dem Bett fällt }\end{array}$ & 40 & 100 & 0 & 8 & -8 & $\begin{array}{l}\text { Latenz- und Reak- } \\
\text { tionszeit ange- } \\
\text { nommen }\end{array}$ & $X, 10$ \\
\hline $\begin{array}{l}\text { 5. Stich am Fußrücken, } \\
\text { lebhafter Unlustaffekt }\end{array}$ & 40 & 100 & 3 & 8 & -5 & $\begin{array}{l}\text { Latenz- und Reak- } \\
\text { tionszeit ange- } \\
\text { nommen }\end{array}$ & $\mathrm{XIV}, 7$ \\
\hline $\begin{array}{l}\text { 6. Der Vp. wird in büsem } \\
\text { Tone der Vorwurf } \\
\text { schlechtenBenehmens } \\
\text { gemacht. Vp. weint } \\
\text { fast }\end{array}$ & 16 & 80 & 3 & 8 & -5 & & IV, 14 \\
\hline 7. Stich in die Wade & 9 & 99 & 8 & 28,7 & $-20,7$ & & $V, 23$ \\
\hline
\end{tabular}

In den folgenden Kurven sind Reaktionsbeispiele sowohl nach unlustbetonten Reizen, als auch bei dauerndem Unlustaffekt dargestellt.

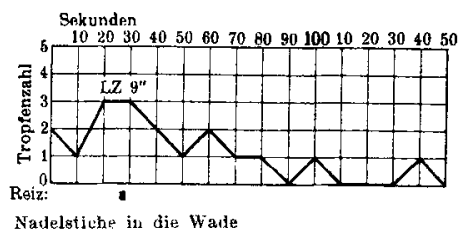

Kurve 16 (Versuch 7, Tabelle 4).

Kurve 16. Nach einem Schmerzreiz auf die im Stimmungsgleichgewicht befindliche Versuchsperson tritt nach sehr kurzer Latenzzeit rasche und ausgiebige Sekretionsabnahme in Erscheinung, welche bis zum vorübergehenden Versiegen des Magensaftflusses fortschreitet. 
Kurve 17. Ebenso wie auf Unlust. affekt nach körperlichem Schmerz tritt auch nach assoziativ erzeugtem Unlustaffekt bei der vorher in physiologischer Stimmung befindlichen Versuchsperson nach kurzer Latenzzeit rasche Abnahme der Magensaftsekretion bis zum völligen Versiegen derselben ein.

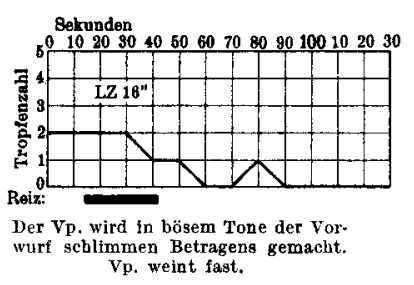

Kurve 17 (Versuch 6, Tabelle 4).

K u rve 18. Der sonst auf denselben Reiz hin erfolgende Sekretionseffekt (siehe Versuche 12, 15, Tab. 2, ferner Kurve 8) bleibt hier vollkommen aus. Es ist berechtigt, den infolge der dauernden Schmerzen

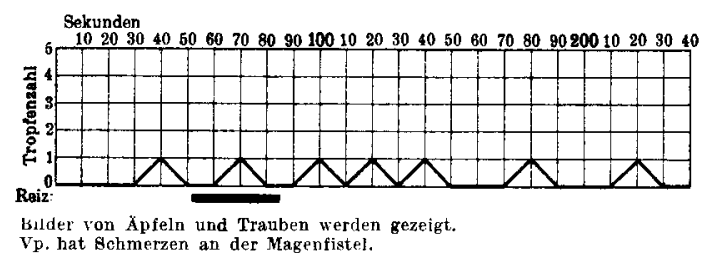

Kurve 18 (Versuch 13, Tabelle 2).

an der Magenfistel dauernd bestehenden Unlustaffekt als Erklärung für diese Erscheinung heranzuziehen, da die reaktive Magensaftsekretion bei analoger Affekteinstellung der Versuchsperson stets in gleicher Weise verändert gefunden wurde.

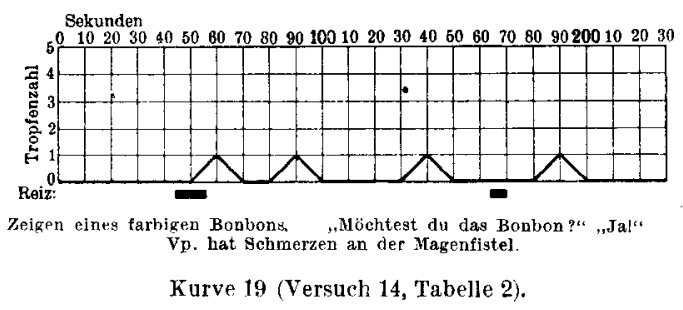

K urve 19. Die Übereinstimmung der Reaktionsabänderung durch den dauernden Unlustaffekt mit der in der vorigen Kurve dargestellten ist ohne weiteres zu ersehen. Auch hier handelte es sich um Reize, welche unter anderen Verhältnissen, bei physiologischer Stimmung der Versuchsperson, stets Steigerung des Magensaftflusses erzeugten (siehe Tab. 2 und 3).

Zur Beurteilung des Effektes von vorübergehendem oder dauerndem Unlustaffekt auf die Magensaftsekretion wolle neben den schon oben angeführten Versuchen aus den Tab. 1-3 auch noch die Kurve 9 herangezogen werden. 


\section{Lustaffekt.}

Bei dem deutlichen Einfluß der Unlust auf die Magensaftabsonderung war es ein naheliegender Gedanke, auch den Effekt von solchen Reizen auf die Sekretion zu prüfen, welche geeignet erschienen, Lustgefühl bei der Versuchsperson zu erzeugen, ohne gleichzeitig das Gemeingefühl anzuregen, welches wir als Appetit bezeichnen. Die Auswahl entsprechender Reize war bei dem kindlichen Alter der Versuchsperson nicht schwierig und sind die bezüglichen Versuche in Tab. 5 zusammengestellt .

Tabelle 5 .

\begin{tabular}{|c|c|c|c|c|c|c|c|}
\hline \multirow{2}{*}{ Reiz } & \multirow{2}{*}{ 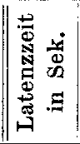 } & \multicolumn{2}{|c|}{ Sekretion } & \multirow{2}{*}{$\begin{array}{c}\text { Durchschnittl. } \\
\text { Sekretion für } \\
\text { diese Zeit } \\
\text { Tropfen }\end{array}$} & \multirow{2}{*}{$\begin{array}{l}\text { Differenz } \\
\text { Tropfen }\end{array}$} & \multirow{2}{*}{ Anmerkungen } & \multirow{2}{*}{$\begin{array}{l}\text { Kurven- } \\
\text { und Reiz } \\
\text { nummer }\end{array}$} \\
\hline & & in Sek. & Tropfen & & & & \\
\hline $\begin{array}{l}\text { 1. Untersucher zeigt sich } \\
\text { der Vp. mit heiterer } \\
\text { Maske. Euphorie der } \mathrm{Vp} \text {. }\end{array}$ & 49,5 & 83 & 13 & 9,9 & $+3,1$ & & $\mathrm{II}, 7$ \\
\hline $\begin{array}{l}\text { 2. Zeigen einer Puppe, die } \\
\text { Vp. versprochen wird }\end{array}$ & 9 & 102 & 20 & 13,2 & $+6,8$ & & III, 14 \\
\hline $\begin{array}{l}\text { 3. Ebenso, keine euphor. } \\
\text { Mimik }\end{array}$ & 40 & 100 & 6 & 13 & -7 & $\begin{array}{l}\text { Latenz- und Re- } \\
\text { aktionszeit an- } \\
\text { genommen }\end{array}$ & $I I r, 7$ \\
\hline $\begin{array}{l}\text { 4. Untersucher zeigt sich } \\
\text { der } V_{\mathrm{p}} \text { mit heiterer } \\
\text { Maske. Euphorie der } V_{\mathrm{p}} \text {. }\end{array}$ & 20 & 65 & 8 & 6,5 & $+1,5$ & & IV, 1 \\
\hline $\begin{array}{l}\text { 5. Zeigen von Spielzeug, } \\
\text { welches der Vp. ver- } \\
\text { sprochen wird. Euphorie } \\
\text { der Vp. }\end{array}$ & 42 & 113 & 17 & 11,3 & $+5,8$ & & IV, 15 \\
\hline $\begin{array}{l}\text { 6. Untersucher zeigt sich } \\
\text { der } \mathrm{V}_{\mathrm{l}} \text {. mit heiterer } \\
\text { Maske. Euphorie der } \mathrm{Vp} \text {. }\end{array}$ & 20 & 85 & 32 & 24,6 & $+7,4$ & & $V, 6$ \\
\hline 7. Zeigen von Spielzeug & 66,5 & 93 & 28 & 26,9 & $+1,1$ & & $\mathrm{~V}, 17$ \\
\hline $\begin{array}{l}\text { 8. Blasen einer Melodie auf } \\
\text { d. Mundharmonika. "War } \\
\text { das schön?" Vp.: "Ja" }\end{array}$ & 32 & 111 & 18 & 13,3 & $+4,7$ & & XIV, 9 \\
\hline
\end{tabular}

Aus der 6. Säule der Tabelle ist ersichtlich, daß lustbetonte Reize in 7 von 8 Versuchen eine reaktive Steigerung des Magensaftflusses gegenüber den durchschnittlichen Sekretionswerten zur Folge hatten. Das eine negative Versuchsergebnis in Versuch 3 ist wohl auf mangelnde Lustreaktion der Versuchsperson zurückzuführen, da im Protokoll das Fehlen euphorischer Mimik auf den Reiz hin ausdrücklich vermerkt erscheint. 
Die Sekretionssteigerung war in keinem Falle eine sehr ausgiebige und blieb hinter den Werten der in Tab. 1-3 berichteten Versuche wesentlich zurück.

Die Latenzzeiten schwanken zwischen 9 und 66,5 Sekunden, der Durchschnittswert beträgt ca. 38 Sekunden.

Eine Proportionalität zwischen Reaktionszeit und Sekretionsgröße konnte auch bei dieser Versuchsreihe nicht gefunden werden.

Aus dem Studium der Originalkurven geht hervor, daß die Reaktionen dieser Versuchsgruppe insofern häufig eine Veränderung gegenüber den Reaktionen nach Appetitreizen zeigen, als der reaktive Saftfluß nicht nur der Menge nach geringer, sondern auch im zeitlichen Ablauf träger und langsamer erfolgte. Diese letztere Erscheinung geht aus der Tabelle nicht hervor, ist aber beim Vergleiche der bezüglichen Kurven mit solchen der früher berichteten Versuchsreihen deutlich erkennbar.

Kurve 20. Die auf den Reiz hin erfolgende Sekretion zeigt in verkleinertem Maßstabe denselben Reaktionstypus, wie er für die größte Zahl der positiv ausge-

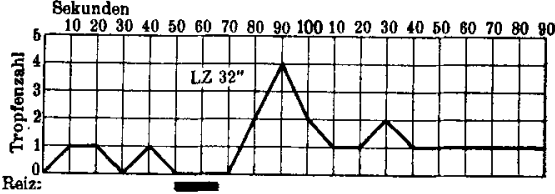

Blasen einer Melodie ani der Mundharmonika. „War das schön ?:t ,Ja!"

Kurve 20 (Versuch 8, Tabelle 5).

fallenen Versuche gefunden wurde. Die initiale Sekretionszacke ist deutlich ausgeprägt, ebenso eine zweite niedrigere Zacke im absteigenden Teil der Sekretion. Der zeitliche Ablauf der ganzen Reaktion erscheint gegenüber Appetitreizen verlangsamt, die Reaktion verläuft träger als nach solchen Reizen.

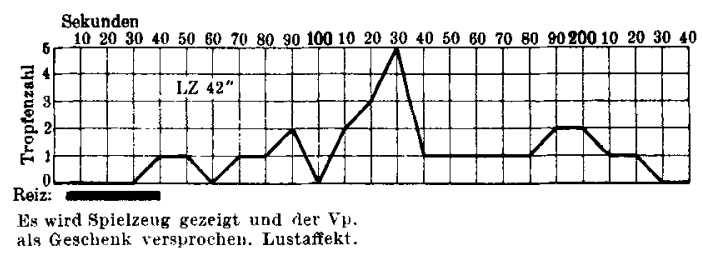

Kurve 21 (Versuch 5, Tabelle 5).

Kurve 21. Der Anstieg des Magensaftflusses erfolgte hier nach dem ersten Reiz in ähnlicher Weise stufenförmig, wie dies sonst im absteigenden Teil der Reaktion beobachtet wurde. Auch in letzterem ist ein geringer Ausdruck phasischen Verlaufes zu erkennen. Der träge Ablauf der ganzen Reaktion tritt in der Kurve deutlich in Erscheinung.

Kurve 22. In diesem Versuche ähnelt der Reaktionstypus viel mehr dem nach Appetitreizen, als in den beiden Kurven 20 und 21 und den übrigen Versuchen dieser Gruppe. Nach kurzer Latenzzeit erscheint eine 


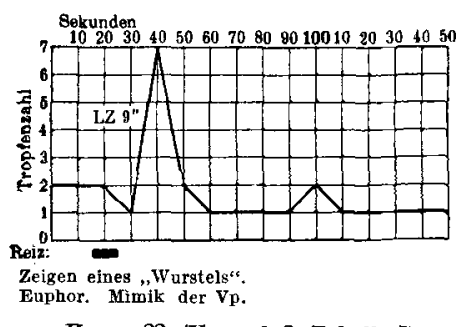

Kurve 22 (Versuch 2, Tabelle 5). initiale Sekretionszacke, die steilen Anstieg und Abfall zeigt. Die Trägheit der reaktiven Sekretion zeigt sich nur in der zeitlichen Verschiebung der zweiten, kleineren Sekretionszacke gegen. über der initialen, sowie in dem langen Bestehen des trägen, gleichmäßigen Saftflusses.

6. Veränderungen der Gemeingefühle. (Schlaf.)

Aus einigen Literaturnachweisen geht hervor, daß dem ,Allgemein. zustande" des Versuchsindividuums, sei es Mensch oder Tier, ein Einfluß auf das Zustandekommen und den Ablauf der reaktiven Magensaftsekretion zugeschrieben wird. In den vorliegenden Versuchen konnte der exakte Nachweis eines solchen Einflusses erbracht werden.

Die hemmende Wirkung eines dauernd bestehenden Unlustaffektes wurde im 4. Abschnitt behandelt:

Aus einer Reihe von Versuchen geht aber außerdem hervor, daß auch das Bestehen des Gemeingefühles ,Schlaf" den auf Reize erfolgenden reaktiven Magensaftfluß hemmend beeinflußt, und zwar im gleichen Sinne wie eine bestehende Unlusteinstellung der Versuchsperson. Wenn das Gemeingefühl "Schlaf" besteht, so erfolgt die im vollwachen Zustande auf entsprechende Reize hin stets auftretende Magensaftsekretion wesentlich vermindert oder sie bleibt überhaupt aus. Ja, es kann auf einen sonst den Magensaftflu $\beta$ steigernden Reiz sogar eine Abnahme der Magensaftsekretion auftreten, wahrscheinlich als Ausdruck des Unlustaffektes, welcher infolge der Störung des bestehenden Schlafbedürfnisses durch den gesetzten Reiz eintritt.

Die bezüglichen Versuche sind zwecks besserer Vergleichsmöglichkeit mit den Versuchen im physiologischen Wachzustande in den Tab. 1-3 vermerkt (Versuch 8, Tab. 1, Versuch 8, Tab. 2, Versuch 10, 15, 16, Tab. 3).

Die folgenden Kurven sollen die Veränderungen des reaktiven Magensaftflusses durch das Gemeingefühl „Schlaf" noch beispielsweise beleuchten

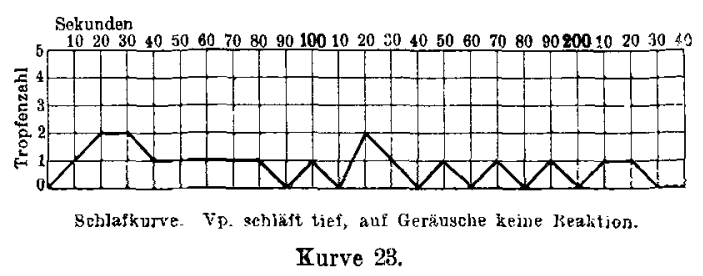

Kurve 23. Diese Kurve zeigt den Ablauf der Magensaftsekretion, wie er während tiefen Schlafes der Versuchsperson beobachtet wurde: Die Versuchsperson, die im Verlaufe des ganzen Tagesversuches schläfrig war, 
schlief endlich ein. Auf Geräusche erfolgte keine Allgemeinreaktion mh $r$ Dar Schlaf wurde weiterhin absichtlich zunächst nicht gestört, um die Magensaftsekretion während desselben zu beobachten.

Es zeigt sich, daß die vom Wachzustande her bestehende Magensaftsekretion im Zustande des tiefen Schlafes keineswegs versiegt, was ja auch aus der Beobachtung der physiologischen Verdauung bekannt ist. Sie zeigt im Gegenteil einen ziemlich gleichmäßigen Verlauf, ohne daß größere Schwankungen, wie sie etwa nach Reizen beobachtet wurden, auftreten.

K urve 24. Der Assoziationsreiz im optischen Sinnesfeld, welcher im physiologischen Wachzustande und Stimmungsgleichgewicht der Versuchsperson stets zu einer ausgiebigen Steigerung des Magensaftflusses führte (Versuch 3, 5, 9, 16, Tab. 2), bewirkte hier einen viel geringeren Effekt. Die Sekretionsgröße auf den Reiz hin blieb sogar gegenüber der durchschnittlichen Tagessekretion zurück (siehe Tabelle).

Aus der Kurve ist jedoch

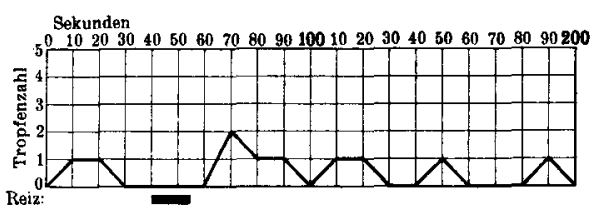

Zeigen von Backwerk. Vp. ist sehr schläfrig.

Kurve 24 (Versuch 8, Tabelle 2). ersichtlich, daß doch ein Reizerfolg eintrat, jedoch ist derselbe ganz gering; die Kurve erscheint gegenüber anderen im Vollwachzustande nach Reizen aufgenommenen verkleinert und zeitlich verkürzt. Der Typus der Sekretion, initiale Sekretionszacke uud phasisches Abklingen, ist jedoch auch in dieser stark herabgesetzten Reaktion deutlich erkennbar.

Kurve 25. Nach dem Assoziationsreiz im akustischen Sinnesfelde blieb bei der fast schlafenden Versuchsperson eine reaktive Veränderung der Magensaftsekretion vollkommen aus.

Ein Vergleich mit dem unmittelbar folgenden Versuche (in Kurve 15 dargestellt), in welchem der akustische Reiz die Versuchsperson wieder im physiologischen Wachzustande traf, zeigt aufs

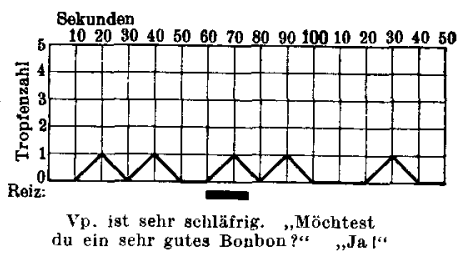

Kurve 25 (Versuch 16, Tabelle 3). deutlichste den gewaltigen Unterschied des reaktiven Magensaftflusses bei Vorhandensein oder bei Fehlen des Gemeingefühles ,,Schlaf".

\section{Aufmerksamkeit.}

Die unerwartete Feinheit und vielfache Gesetzmäßigkeit der auf Reize erfolgten reaktiven Magensaftsekretion, dann die Tatsache, daß Schlaf der Versuchsperson die Veränderungen des Magensaftflusses verringerte oder unterdrückte, ließen es wünschenswert erscheinen; 
auch den Einfluß der einfachen Aufmerksamkeitseinstellung auf die Magensekretion zu prüfen. Die bezüglichen Versuche sind in Tab. 6 zusammengestellt.

Tabelle 6.

\begin{tabular}{|c|c|c|c|c|c|c|c|}
\hline \multirow{2}{*}{ Reiz } & \multirow{2}{*}{ 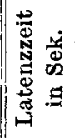 } & \multicolumn{2}{|c|}{ Sekretion } & \multirow{2}{*}{$\begin{array}{l}\text { Durchschnittl. } \\
\text { Sekretion für } \\
\text { diese Zeit. } \\
\text { Tropfen }\end{array}$} & \multirow{2}{*}{$\begin{array}{l}\text { Differenz: } \\
\text { Tropfen }\end{array}$} & \multirow{2}{*}{ Anmerkungen } & \multirow{2}{*}{$\begin{array}{l}\text { Kurven- } \\
\text { und Reiz- } \\
\text { nummer }\end{array}$} \\
\hline & & in Sek. & Tropfen & & & & \\
\hline $\begin{array}{l}\text { Zeigen von Bildern von } \\
\text { Pferd und Kuh }\end{array}$ & 40 & 100 & 8 & 6 & +2 & $\begin{array}{l}\text { Latenz- und Re- } \\
\text { aktionszeit an- } \\
\text { genommen }\end{array}$ & VII,1 \\
\hline $\begin{array}{l}\text { Zeigen von Bildern von } \\
\text { Katze und Maus }\end{array}$ & 40 & 100 & 9 & 6 & +3 & Ebenso & VII,2 \\
\hline Fünfmal Kuckucksruf & 40 & 100 & 4 & 6 & -2 & Ebenso & VII,5 \\
\hline $\begin{array}{l}\text { Zeigen eines Bildes von } \\
\text { einem Hasen }\end{array}$ & 40 & 100 & 5 & 5 & 0 & Ebenso & IX, 5 \\
\hline Glockenläuten & 40 & 100 & 7 & 7 & 0 & Ebenso & $\mathrm{XII}, 2$ \\
\hline $\begin{array}{l}\text { Plötzlicher starker Lârm } \\
\text { im Vorraum }\end{array}$ & 40 & 100 & 11 & 8 & +3 & Ebenso & $\mathrm{X}, 3$ \\
\hline
\end{tabular}

Aus dera auf Tab. 6 zusammengestellten Versuchsergebnissen geht hervor, daß die einfache Aufmerksamkeitseinstellung ohne Affekterregung und ohne assoziative Erregung von Vorstellungen, welche mit dem Gemeingefühl „Appetit" verknüpft sind, keinen Einfluß auf die Magensaftsekretion haben.

In keinem Versuche trat eine solche Veränderung des Magensaftflusses auf, daß Latenz- und Reaktionszeit festgestellt werden konnten. Die schwankenden Differenzen zwischen der während der angenommenen Reaktionszeit beobachteten Tropfenzahl und der durchschnittlichen Sekretion des Tagesversuches finden ihre Erklärung eben in der Annahme der Reaktionszeiten, welche angesichts der fehlenden Reaktion zwecks vergleichender Darstellung nötig war.

Aus den bemerkenswerten Ergebnissen der im vorstehenden berichteten Versuche ergaben sich eine Reihe von weiteren Fragen, unter denen besonders die nach dem Zusammenhange der vasomotorischen Begleiterscheinungen psychischer Zustände und der reaktiven Magensaftsekretion interessant erschien.

Es wurde daher an einer zweiten Versuchsperson (W.F.) eine Reihe von Versuchen begonnen, bei welchen der Magensaftfluß und das Armvolumen gleichzeitig registriert wurden. Bei dem bekannten Antagonismus zwischen Blutfüllung der Extremitäten und der Eingeweide konnten aus den Schwankungen des Armvolumens Schlüsse auf die Blutfüllung der Eingeweide, im besonderen der Magenwand, gezogen werden. 
Studien üb. d. Einfl. d. Großhirntätigk. auf d. Magensaftsekretion d. Menschen. 291

Leider ist diese Versuchsreihe aus zwei Gründen mangelhaft. Erstens deshalb, weil die Oesophagusstenose bei der Versuchsperson durch einen malignen Tumor verursacht war; infolgedessen war das Individuum körperlich sehr herabgekommen und psychisch in einem dauernden leichten Unlustaffekt, welcher nach den Ergebnissen der früheren Versuchsreihe an und für sich die reaktive Magensaftsekretion im Sinne einer Hemmung beeinflussen mußte.

Ferner mußten die Versuche aus äußeren mißlichen Umständen sehr bald wieder abgebrochen werden, so daß die Ergebnisse dieser Versuchsreihe keinen Anspruch auf Vollständigkeit machen können.

Daher können die Versuchsergebnisse der zweiten Reihe hier nur im Zusammenhange mit denen der ersten betrachtet und verwertet werden. Es ist beabsichtigt, die bezüglichen Fragen an weiteren geeigneten Versuchspersonen, deren Vorhandensein natürlich Sache des Zufalles ist, in neuerlichen Versuchsreihen zu studieren.

Die verwertbaren Ergebnisse der zweiten Reihe sind nur als Kurven dargestellt, da eine tabellarische Cbersicht der geringen Anzahl wegen überflüssig erscheint.

Kurve 26. Auf den Assoziationsreiz im optischen Sinnesfelde trat zunächst eine typische Aufmerksamkeitsschwankung (a) des Armvolumens in Erscheinung. Nach Ablauf derselben erfolgte ausgiebige Volumsteigerung am Arme (b), wie sie physiologisch bei jedem Lustaffekt, und auf einen solchen war aus der Mimik und dem Tonfall der sprachlichen Äußerung der Versuchsperson zu schließen, beobachtet wird.

Erst als die vasomotorische Reaktion schon fast beendet

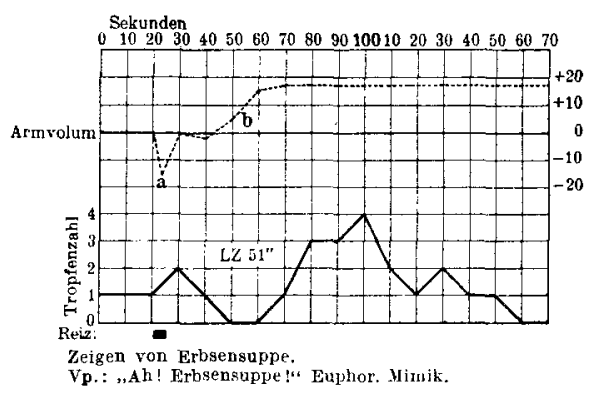
Kurve 26. war, 51" nach dem Reiz, setzte eine Steigerung des Magensaftflusses ein, welche in ziemlich typischer Weise mit initialer.Sekretionszacke und phasischem Abklingen der Sekretion verlief. Nur ist die initiale Sekretionszacke niedrig und länger gestreckt, als dies bei den meisten Versuchen an der ersten Versuchsperson beobachtet wurde.

Die Steigerung des Armvolumens und damit die daraus zu schlieBende Senkung des Volumens der Bauchgefäße fällt in die Latenzzeit der reaktiven Magensekretionssteigerung.

Kurve 27. Sofort nach dem Assoziationsreiz im akustischen Sinnesfeld erfolgte kurze Steigerung, darauf folgende Senkung und neuerliche Steigerung des Armvolumens als vasomotorischer Ausdruck der Aufmerksamkeitseinstellung (a). Die hierauf folgende starke Abnahme des Arm- 
volumens $\left(b-b_{1}\right)$ konnte sowohl als vasomotorische Unlustreaktion als auch als Begleiterscheinung geistiger Arbeit aufgefaßt werden; nach den

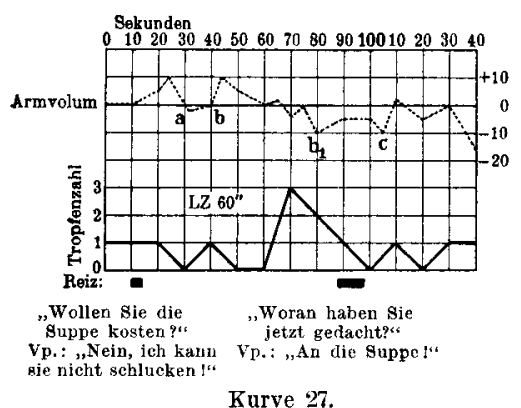

Antworten der Versuchsperson auf die beiden Reizfragen ist dieAnnahme zulässig, daß beide Komponenten, Unlust und Assoziationstätigkeit, an dem Zustandekommen der starken Armvolumsenkung beteiligt waren. Die kurze Senkung und nachherige Steigerung des Armvolumens bei $c$ entspricht der Aufmerksamkeitsschwankung auf die zweite Reizfrage.

Trotz der ablehnenden Antwort auf die erste Reizfrage kam es nach $60^{\prime \prime}$ zu einer reaktiven Steigerung des Magensaftflusses; dieselbe war wie in Kurve 26 geringgradig, die Sekretionszacke ist niedrig und langgestreckt, besonders im absteigenden Anteil. Ein phasisches Abklingen der Sekretion ist hier nicht deutlich ausgeprägt.

Die Armvolumschwankungen und besonders die Senkung des Armvolumens $(b-b)$, daher auch die zu postulierende Volumszunahme der Bauchgefäße fallen fast zur Gänze in die Latenzzeit der reaktiven Magensaftsekretion.

K u r v e 28. In diesem Versuche trat nach der typischen Aufmerksamkeitsschwankung des Armvolumens ( $a$ ) zunächst langsame Senkung, dann

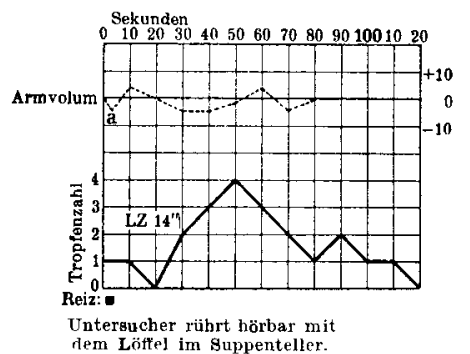

Kurve 28 . ebenso langsame Steigerung des Armvolumens ungefähr in gleicher Intensität in Erscheinung.

Der reaktive Magensaftfluß erfolgte nach sehr kurzer Latenzzeit $\left(14^{\prime \prime}\right)$ in typischer Weise mit initialer Sekretionszacke und phasischem Abklingen; erstere ist auch hier wieder auffallend niedrig und langgestreckt, was einer wenig ausgiebigen und träge verlaufenden Sekretionssteigerung entspricht.

Der absteigende Schenkel der Armvolumkurve, welchem eine gesteigerte Blutfülle der Bauchgefäße entspricht, fällt in die Latenzzeit der Magensaftsekretion, an den aufsteigenden Schenkel der Armvolumkurve (Absinken der Blutfüllung der Bauchgefäße) schließt sich der absteigende Schenkel der Magensaftsekretion unmittelbar an.

K u rve 29. Ein dem im vorigen Versuch verwendeten ganz ähnlicher akustischer Assoziationsreiz rief an der Kurve des Armvolumens zunächst die typische Aufmerksamkeitsschwankung (a) hervor, dann erfolgte eine 
langsame, zweimal durch kurze Hebungen unterbrochene Senkung der Armvolumkurve.

Die reaktive Magensaftsekretion setzte erst nach $63,5^{\prime \prime}$ ein; sie verlief wie immer bei dieser Versuchsperson träge und wenig ausgiebig und in diesem Falle atypisch in der Hinsicht, als sie nicht initial am stärksten einsetzte, sondern allmählich stufenförmig anstieg. Die Unterbrechung des absteigenden Kurvenschenkels ist wohl als Ausdruck des phasischen Abklingens der Reaktion aufzufassen.

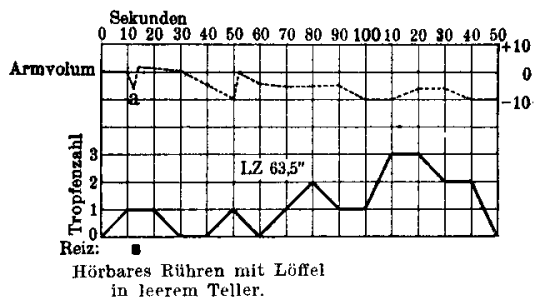

Kurve 29 .

Der größere Teil der Armvolumsenkung, also der Volumzunahme der Bauchgefäße fällt in die Latenzzeit des reaktiven Magensaftflusses.

K u r ve 30 . Die beiden Reize, von denen der zweite ein Assoziationsreiz im olfaktorischen Sinnesfelde war, führten zunächst zu zwei entsprechenden Aufmerksamkeitsschwankungen der Armvolumkurve $\left(a, a^{1}\right)$. Dann erfolgte eine typische Lustreaktion des Armvolumens, starkes Ansteigen mit nachfolgendem Absinken auf die Ausgangsgröße; dieser Volumschwankung entspricht die entgegengesetzte an den Blutgefäßen der Bauchhöhle, also zunächst starke $\mathrm{Ab}$ -

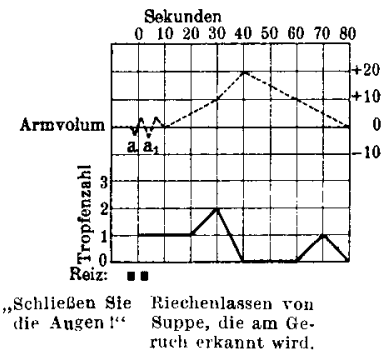

Kırve 30. nahme und nachheriges Ansteigen ihrer Füllung bis zur Ausgangsgröße.

Eine reaktive Zunahme der Magensaftsekretion, wie sie auf den Appetitreiz im olfaktorischen Sinnesfelde zu erwarten gewesen wäre, blieb hier vollkommen aus, eher ist aus der Kurve eine Abnahme des Magensaftflusses zu entnehmen, welche auf die Volumzunahme des Armes folgt.

K u r v e 31. Auf den Assoziationsreiz im olfaktorischen Sinnesfeld erfolgte eine sehr starke und rasche Schwankung des Armvolumens (a), welche dem Typus der Aufmerksamkeitsreaktion gleicht, aber viel größere Ausschläge im positiven und negativen Sinne zeigt, als dies bei der Aufmerksamkeitsschwankung gewöhnlich der Fall ist. Die Atemveränderung beim Riechakte dürfte beim Zustandekommen dieser starken Volumschwankung vielleicht

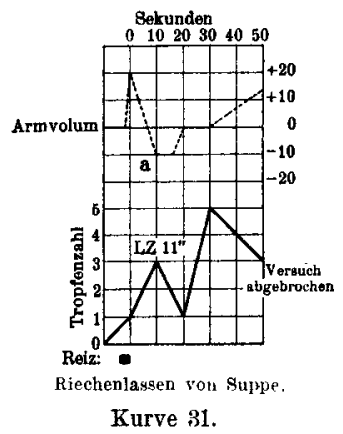
mit eine Rolle spielen. Nach derselben nahm das Armvolumen bis zum Ende desVersuches rasch zu, was einer Reaktion auf Lustaffekt entspricht. 
Die Magensaftsekretion stieg nach sehr kurzer Latenzzeit sehr rasch und stufenförmig an, das Absinken des Magensaftflusses konnte nicht mehr beobachtet werden, da der Versuch wegen Auslaufens der Kymographenschleife abgebrochen werden mußte.

Die starke Volumsenkung des Armes bei $a$, welche einer Steigerung der Gefäßfüllung der Bauchorgane entspricht, fällt in die Latenzzeit der reaktiven Magensaftsekretion.

Kurve 32. Der unlustbetonte Reiz hatte zunächst eine starke Aufmerksamkeitsschwankung des Armvolumens $(a-b)$, dann eine langsame

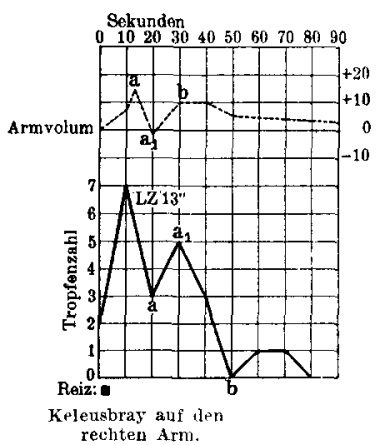

Kurve 32 . Senkung desselben als Ausdruck des Unlustaffektes, welchen der Reiz auslöste, zur Folge.

Die von einem anderen Reiz her bestehende Magensaftsekretion zeigt auf den unlustbetonten Reiz hin nach kurzer Latenzzeit yon $13^{\prime \prime}$ rasche und ausgiebige Abnahme bis zum zeitweiligen Versiegen des Magensaftflusses.

Die Magensekretionskurve und die Armvolumkurve verlaufen gegensinnig, jedoch so, daß die Schwankungen des Magensaftflusses gegenüber denen des Armvolumens verspätet erscheinen; die korrespondierenden Hebungen und Senkungen beider Kurven sind mit gleichen Buchstaben $\left(a, a_{1} b\right)$ bezeichnet, Zunahme und Abnahme des Armvolumens entspricht den entgegengesetzten Schwankungen der Blutfülle der Bauchgefäße; die Schwankungen des Magensaftflusses verlaufen also mit letzteren gleichsinnig, aber zeitlich verspätet.

\section{Zusammenfassung der Versuchsergebnisse.}

Entsprechend dem oben in der Vorbesprechung der Versuche an der zweiten Versuchsperson Gesagten sollen hier zunächst nur die Ergebnisse der Versuche an der ersten Versuchsperson zusammenfassend besprochen werden. Die Versuchsergebnisse an der zweiten Versuchsperson (Kurve 26-32) sollen damit erst am Schlusse in Zusammenhang gebracht und verglichen werden.

Die Ergebnisse der Versuche an der Versuchsperson K. J. (Tab. 1 bis 6 , Kurve 1-25) lassen sich ungefähr folgendermaßen zusammenfassen:

Im nüchternen Zustande und bei gereinigtem Magen werden auch bei vollkommenem Fehlen differenter äußerer Reize dauernd geringe Mengen von Magensaft ausgeschieden, deren tropfenweiser Abfluß aus der Magenfistel in längeren Zeitabschnitten in ziemlich regelmäßigen Intervallen erfolgt. Diese spontane Magensaftsekretion versiegt nicht einmal im Schlafe. 
Reize verschiedener Qualität steigern oder hemmen die spontane Magensaftsekretion, was in der Verkürzung oder Verlängerung der Zeitintervalle zwischen den einzelnen Tropfen zum Ausdruck kommt.

Physiologische Reize von der Schleimhaut der Mundhöhle a us rufen nach einer Latenzzeit unter allen Umständen Steigerung der Magensaftsekretion hervor, wenn beim Individuum Stimmungsgleichgewicht und das physiologische Gemeingefühl des Wachseins vorhanden sind.

Die Latenzzeiten, welche vom Beginn des Schleimhautreizes his zum Einsetzen der Magenflußsteigerung verstrichen, sind verschieden groß gefunden worden, obwohl der Reiz immer derselbe war. Die Unterschiede der Latenzzeiten sind recht beträchtliche, die gefundenen Latenzperioden schwanken zwischen 31 und 118"; ihr Mittel beträgt für diese Reizgruppe $75^{\prime \prime}$.

Auch die Werte der Reaktionszeiten, der absoluten und der relativen Selretionssteigerung (Differenz zwischen reaktiver und durchschnittlicher Sekretion) weisen bei den einzelnen Versuchen untereinander große Schwankungen auf.

Diese Schwankungen folgen keinerlei erkennbaren Gesetzen; insbesondere ist weder die Größe der absoluten noch die der relativen Sekretionssteigerung von der Reaktionszeit oder der Latenzzeit abhängig.

Reize im optischen und akustischen Sinnesfeld, welche auf assoziativem Wege eine Vorstellung verursachen, mit der das Gemeingefühl ,Appetit" verknüpft ist, rufen unter denselben inneren Bedingungen wie die erste Gruppe von Reizen nach einer Latenzzeit ebenfalls Steigerung der Magensaftsekretion hervor.

Die Latenzzeiten für diese beiden Reizgruppen wurden ebenfalls sehr verschieden, jedoch wesentlich geringer gefunden als für Schleimhautreize von der Mundhöhle aus; ihr Durchschnittswert betrug für optische Reize $48^{\prime \prime}$, für akustische sogar nur $39^{\prime \prime}$.

Sehr kurze Latenzzeiten wurden bei beiden Reizgruppen in Versuchen festgestellt, in welchen eine Kumulierung gleichartiger Reize stattgefunden hatte.

Die Reaktionszeiten, die absolute und die relative Sekretionssteigerung, zeigten sich bei diesen beiden Reizgruppen ebenso unregelmäßigen Schwankungen unterworfen wie bei der ersten Reizgruppe; eine Gesetzmäßigkeit dieser Schwankungen war hier ebenfalls nicht aufzúfinden.

Die absolute und relative Sekretionssteigerung nach optischen Assoziationsreizen wurde im ganzen niedriger gefunden als die nach physiologischen Schleimhautreizen.

Dagegen erreichten nach akustischen Assoziationsreizen die Werte 
der Sekretionssteigerungen nicht nur die nach physiologischen Schleimhautreizen gefundenen in mehreren Versuchen, sondern übersteigen sie sogar in einzelnen Fällen.

In einer Anzahl von Versuchen mit optischen Assoziationsreizen wurde eine deutliche Abhängigkeit der Größe der reaktiven Magensekretion von der Qualität der angebrachten Reize beobachtet.

Experimentell erzeugter Lustaffekt ohne das Gemeingefühl „A p petit" verursacht ebenfalls eine reaktive Steigerung des Magensaftflusses.

Die schwankenden Latenzzeiten nach Lustreizen hielten sich im Durchschnitte ungefähr in derselben Höhe, wie die nach Assoziationsreizen im akustischen Sinnesfelde.

Die Schwankungen der Reaktionszeiten, der absoluten und relativen Sekretionssteigerung, welche sich in den einzelnen Versuchen zeigten, folgen nach lustbetonten Reizen ebensowenig erkennbaren Gesetzen, wie dies für die Reize von der Mundhöhle aus, im optischen und akustischen Sinnesfelde der Fall war.

Die absolute und relative Sekretionssteigerung nach lustbetonten Reizen ohne Appetiterregung blieb an Größe hinter der Magensaftflußsteigerung, welche bei den bisher besprochenen drei Reizgruppen beobachtet wurde, wesentlich zurück; auch erfolgte sie gegenüber letzterer träger und langsamer.

Der gesteigerte Abfluß von Magensekret erfolgt nach Reizen aller vier bisher besprochenen Gruppen in den meisten Fällen nach einem bestimmten Typus. Derselbe besteht darin, daß zunächst eine rasche stürmische Steigerung des Magensaftflusses in Erscheinung tritt, die ebenso rasch wieder abklingt und von einer Reihe ähnlicher aber geringerer, manchmal stufenweise absteigender Steigerungen des Saftflusses gefolgt ist. Die reaktive Steigerung des Magensaftflusses zeigt also in der Mehrzahl der Fälle phasenartigen Verlauf, wobei die erste Phase des Einsetzens der Reaktion die höchste ist und die folgenden an Größe oft um ein Vielfaches übertrifft.

Dieser Typus des Magensaftabflusses erscheint in einigen Versuchen abgeändert, in einzelnen sogar verkehrt in dem Sinne, daß auch die Steigerung stufenweise erfolgt.

Unlustaffekt hemmte die Magensaftsekretion in allen Fällen, sei es, daß er experimentell erzeugt wurde, sei es, daß er bei der Versuchsperson als Affekteinstellung dauernd bestand.

Die Hemmungswirkung bestand entweder darin, daß die Magensaftsekretion nach unlustbetonten Reizen abnahm, oder aber darin, daß der im Stimmungsgleichgewicht stets beobachtete Effekt von sekretionssteigernden Reizen vermindert wurde, ja überhaupt ausblieb.

Die Wirkungen des Unlustaffektes und des I ustaffektes 
a uf die Magensaftsekretion verhalten sich also gerade entgegengesetzt.

Die Latenzzeit zwischen unlustbetontem Reiz und hemmenden Effekt auf den Magensaftfluß scheint sehr kurz zu sein.

Das Vorhandensein des Gemeingefühles Schlaf hemmt die reaktive Magensaftsekretion in demselben Sinne wie dauernde Affekteinstellung der Unlust, indem die zu erwartende sekretionssteigernde Wirkung von Reizen stark verringert wird oder fehlt. Die öfter beobachtete Abnahme des Magensaftflusses, welche bei Schläfrigkeit der Versuchsperson nach sonst sekretionssteigernden Reizen beobachtet wurde, ist wahrscheinlich auf den Unlusteffekt zurückzuführen, welchen jede Störung des Gemeingefühls Schlaf nach allgemeiner Erfahrung auslöst.

Die spontane Magensaftsekretion setzt sich im Schlafzustande, wenigstens während der relativ kurzen Dauer der Beobachtung in diesen Versuchen, unverändert fort.

A ufmerksamkeitseinstellung allein hat keinen deutlichen Einfluß auf die Magensaftsekretion.

Die Versuche an der zweiten Versuchsperson bestätigten die an der ersten gemachten Beobachtungen.

Auch in diesem Falle wurde in nüchternem Zustande und bei gereinigtem Magen spontane Magensaftsekretion gefunden, welche sich auf Reize quantitativ veränderte.

Bei Beurteilung der Reaktionen des Magensaftflusses auf Reize bei der zweiten Versuchsperson muß in Rücksicht gezogen werden, daß infolge des schweren Krankheitszustandes dieses Falles dauernde Affekteinsteliung im Sinne der latenten Unlust vorhanden und daher von vornherein zu erwarten war, daß die Intensität der reaktiven Magensaftsekretion geringer sein müsse, als bei dem erstuntersuchten Falle. Daß die Reaktionen des Magensaftflusses auf Reize bei dem zweiten Falle tatsächlich durchwegs viel geringer gefunden wurden als bei der ersten Versuchsperson, erbringt einen weiteren Beweis für die hemmende Wirkung dauernden Unlustaffektes auf die Magensaftsekretion.

Aus den Versuchen am zweiten Falle geht ferner hervor, daß Assoziationsreize im optischen und akustischen. Sinnesfelde, mit welchen die Vorstellung Essen und das Gemeingefühl Appetit verknüpft sind, ebenso wie in der Versuchsreihe an der ersten Versuchsperson stets Steigerung der Magensaftsekretion zur Folge hatten, aber gehemmt durch den vorhandenen latenten Affekt der Unlust.

Die festgestellten Latenzzeiten bei der zweiten Versuchsperson stimmen mit den bei der ersten gefundenen gut überein.

Die beiden Versuche mit Assoziationsreizen in olfaktorischen 
Sinnesfelde (Kurve 30, 31) haben ungleiche Resultate ergeben und sind nur in Hinsicht des Verhältnisses zwischen vasomotorischer Blutgefäßeinstellung und Magensaftsekretion interessant. Hinsichtlich der Magensaftsekretion geht daraus nur hervor, daß dieselbe auch durch Geruchsreize angeregt werden kann, daß dies aber nicht immer der Fall zu sein braucht, auch wenn der Geruchsreiz an und für sich Lustaffekt hervorruft (Armvolumen Kurve 30).

Experimentell erzeugter Unlustaffekt hatte auch in diesem Falle rasches Absinken der Magensaftsekretion zur Folge; er hemmte dieselbe also in genau derselben Weise wie in den Versuchen an der ersten Versuchsperson.

Die Kurve des Armvolumens gestattet infolge des Antagonismus der Blutgefäße der Extremitäten und der Bauchorgane einen direkten Schluß auf die Blutfüllung der letzteren.

Wenn die Kurve des Armvolumens sinkt, so bedeutet dies eine Steigerung der Blutfülle der Bauchorgane und umgekehrt.

Behufs besseren Verständnisses der Zusammenhänge zwischen reaktiver Magensaftsekretion und Einstellung der Blutgefäße auf Reize soll daher im folgenden dieser Schluß gleich gezogen und nicht die Volumveränderungen des Armes, sondern die Schwankungen der Blutfüllung der Bauchorgane zur Betrachtung herangezogen werden.

In fünf Versuchen an der zweiten Versuchsperson ist aus den Kurven des Armvolumens und der Magensekretion zu ersehen, daß einer Steigerung des Magensaftflusses stets eine Vermehrung der Blutfüllung der Bauchorgane vorangeht (Kurve 27, 28, 29, 31, 32). Umgekehrt folgt auf Sinken der Füllung der Bauchgefäße in mehreren Fällen Abnahme des Magensaftflusses (Kurve 30, 28, 32). Letztere Erscheinung ist seltener und nicht so auffällig wie erstert. In einem Falle (Kurve 26) ist ein solches Zusammentreffen nicht ersichtlich.

\section{Schlußfolgerungen.}

Die vorliegenden Versuche führen zur Kenntnis einiger Tatsachen, welche bisher noch nicht bekannt waren.

Zunächst gelang es, mittels der verfeinerten Methodik, die Latenzzeit zwischen Reiz und Reaktion der Magensaftsekretion genau festzustellen.

Die in vorliegenden Untersuchungen gefundenen Latenzzeiten unterscheiden sich wesentlich von denen, welche Hornbog und Bickel für den Menschen angegeben haben. Während jener 6--7 Minuten, dieser 4-5 Minuten als Latenzzeiten für den reaktiven Magensaftfluß annimmt, konnte ich als größte Latenzzeit nur 118", also noch nicht 2 Minuten, feststellen. Dieser hohe Wert zeigte sich nur einmal beim Kauen von Nahrungsmitteln, bei welcher Reizgruppe überhaupt die 
größten Latenzzeiten zwischen Reiz und reaktiver Magensekretion gefunden wurden.

Die Latenzzeiten nach optischen und akustischen Reizen, welche appetitbetonte Vorstellungen hervorriefen, erwiesen sich wesentlich niedriger, als die nach Kaureizen. Diese zunächst eigentümliche Tatsache wird verständlich, wenn wir uns daran erinnern, daß die Raschheit der für die Apperzeption des Reizes nötigen Reizaufnahme und Reizleitung im optischen und akustischen Sinnesfelde eine ungleich höhere ist als im gustatorischen und olfaktorischen, welch letztere bei der Aufnahme und Leitung von Kau- und Geschmacksreizen die wesentlichste Rolle spielen. Ferner wird in Utberlegung zu ziehen sein, daß durch die Organisation des menschlichen Gehirns - wohl im Gegensatz zu dem vieler anderer Tierarten -.. die assoziative Erregung anderer Hirnteile nach optischen und akustischen Sinneseindrücken rascher erfolgt als nach Geschmacks- und Geruchsreizen. Mit anderen Worten, die Differenzen der gefundenen Latenzzeiten des reaktiven Magensaftflusses nach Kaureizen einerseits, nach assoziationserregenden Gesichts- und Gehörsreizen anderseits sind aufzufassen als Teilausdruck der arteigenen Organisation derGenus Mensch als einer vorwiegend optisch und akustisch orientierten Tierart.

Die vorliegenden Untersuchungen haben ferner gezeigt, daß die in geringem Grade stets bestehende Tätigkeit der menschlichen Magendrüsen durch mannigfache, qualitativ sehr verschiedene Reize beeinflußt wird.

Sekretionssteigernd wirken:

Kauen von Nahrungsmitteln.

Optisch assoziativ erregte Vorstellung von Nahrungsmitteln.

Akustisch assoziativ erregte Vorstellung von Nahrungsmitteln.

Akustisch assoziativ erregtes Gemeingefühl „Hunger".

Lustaffekt (ohne das Gemeingefühl ,Appetit“).

Sekretionshemmend wirken:

Vorübergehender Unlustaffekt.

Dauernder latenter Unlustaffekt | Herabsetzung oder Aufhebung Das Gemeingefühl ,Schlaf“" $\}$ der Wirkung sekretionssteigernder Reize.

Innerhalb einzelner Reizgruppen bestehen außerdem noch quantitative Unterschiede der Wirkung nach der Qualität der Reize, was besonders für das optische Sinnesfeld festgestellt werden konnte.

Zum Zustandekommen einer reaktiven Steigerung des Magensaftflusses genügt offenbar die assoziativ entstandene Vorstellung von Nahrungsmitteln allein, ohne daB 
damit eine Bereitschaft zur Nahrungsaufnahme verknüpft ist; dies wird durch die Tatsache bewiesen, daß Anblick bildlicher Darstellungen von Nahrungsmitteln und Sprechen von durch andere Individuen genossenen Nahrungsmitteln die Magensaftsekretion steigert. (Versuch 12, 15, Tab. 2, Versuch 13, 14, Tab. 3.)

Die Kenntnis aller dieser Umstände ermöglicht eine befriedigende Erklärung dafür, daßs Latenzzeit, Reaktionszeit, absolute und relative Steigerung oder Verminderung des Magensaftflusses innerhalb der Versuche sowohl mittels einer Reizgruppe, ja desselben Reizes, als auch mittels verschiedenartiger Reize so große und unregelmäßige Verschiedenheiten ergeben haben. Die sezernierende Tätigkeit der Magendrüsen kann ja durch Reize aller der oben angeführten Arten und wohl noch durch solche anderer, zum Großteil noch unbekannter Arten beeinflußt werden; und ein experimentell gesetzter Reiz kann niemals mit Sicherheit so gewählt und angebracht werden, daß gleichzeitig die Wirkung anderer Nebenreize, beispielsweise der Affektlage und der Gemeingefühle, vollkommen ausgeschaltet wird. Mit anderen Worten: jede reaktive Veränderung der Magensaftsekretion beim Menschen ist ein Produkt der Wirkung von Reizen sehr verschiedener Art. Das jeweilige Verhältnis dieser Reize untereinander ( $\mathrm{K}$ umulierung, Interpolation usw.), von welchen nur ein Teil in vorliegender Arbeit a uf ihre Wirksamkeit geprüft wurde, schafft unendlich vielfache Bedingungen für das Zustandekommen von Steigerung und Hemmung der Magensaftsekretion.

Von besonderer auch praktischer Wichtigkeit sind die Versuchsergebnisse, welche dartun, daß außer der bereits bekannten hemmendenWirkungderUnlust a uf die Magensaftsekretion (Bickel, Hornbog, Skray) auch das Gemeingefühl "Schlaf" eine starke Hemmung des reaktiven Magensaftflusses bedingt. Es liegt darin ein Hinweis darauf, daß die Ausnützung von Nahrungsmitteln durch den Organismus bei Aufnahme derselben im ermüdeten Zustande eine schlechtere sein muß, als beim Fehlen der Ermüdung.

Ebenso interessant ist der Antagonismus von reinem Lustund Unlustaffekt auf die reaktive Magensaftsekretion, welcher in den vorliegenden Versuchen festgestellt werden konnte. Die Wirkkungen von Lust und Unlust auf die Magensaftsekretion verhalten sich ähnlich entgegengesetzt wie die auf die vasomotorische Einstellung der Blutgefäße. Auch in dieser Feststellung sind wertvolle praktische Hinweise für die Abhängigkeit cler Ausnützung aufgenommener Nahrungsmittel von der Stimmungslage des essenden Individuums enthalten. 
Eine eigentümliche Erscheinung ist der so häufig wiederkehrende Typus der reaktiven Magensaftsekretion mit stürmischem Einsetzen und phasenhaftem Abklingen des Magensaftflusses. Ob hierbei die Motilität des Magens eine Rolle spielt, konnte mittels der in Anwendung gekommenen Methodik nicht festgestellt werden.

Es erscheint bemerkenswert, daß der häufig beobachtete Typus des Verlaufes einer reaktiven Steigerung des Magensaftflusses viel Ähnlichkeit mit dem der Reaktionen der Vasomotilität des übrigen Körper: anfweist. Auch an der Volumkurve beispielsweise des Armes tritt auf einen Reiz hin zunächst eine rasche Volumänderung ein, welche sich dann langsamer und oft unter Schwankungen wieder ausgleicht (siehe z. B. Armvolumen auf Kurve 28).

Vielleicht liegt in der häufig beobachteten Ähnlichkeit der beiden Erscheinungen ein Hinweis auf eine Abhängigkeit der Magensekretion von der vasomotorischen Gesamteinstellung und deren Einfluß auf die Blutfülle der Bauchorgane.

Daß nach entsprechenden Reizen sich die Gefälße der Magenschleimhaut mit Blut füllen, hat schon Richet am Hunde nachgewiesen. Es erscheint ja auch erwiesen, daß eine Bedingung für die gesteigerte Tätigkeit von Drüsen ihre bessere Blutversorgung ist.

In dieser Hinsicht erscheint es interessant, daß in den vorliegenden Versuchen bei gleichzeitiger Registrierung des Armvolumens und des Magensaftflusses in fünf von sechs Versuchen festgestellt werden konnte, daß einer Steigerung der Magensaftsekretion eine Steigerung der Blutfüllung der Bauchorgane voranging.

Dies weist darauf hin, da $B$ für die Aktivierung der Magendrüsen die vasomotorische Reaktion a uf einen Reiz maßgebend mit in Betracht kommt.

Die reaktive Veränderung der Blutfüllung der Bauchorgane ist aber offenbar nicht die einztge Bedingung für die Tätigkeit der Magendrüsen, da der Zusammenhang zwischen vasomotorischer Einstellung und Tätigkeit der Magendrüsen keine durchgängige Erscheinung ist. Wir werden eine weitere Bedingung für die Funktion der Magendrüsen in einem direkten nervösen, Einfluß auf dieselben zu suchen haben, welcher ihre vasomotorische Aktivierung regulativ beeinflußt. Ein direkter nervöser Einfluß a uf die Magendrüsen kommt ferner zweifellos für den Teil ihrer Tätigkeit in Betracht, welcher seinen Ausdruck in einer verschiedenen qualitativen Zusammensetzung des ausgeschiedenen Sekretes findet. 


\section{Literaturverzeichnis.}

A llers, Nervensystem und Stoffwechsel. Zeitsehr. f. d. ges. Neur. u. Psych. Ref. 19, 1919. - Beaumont, Neue Versuche und Beobachtungen über den Magensaft und die Physiologie der Verdauung. Leipzig 1834. - Bech terew, Funktionen der Nervenzentra. Bd. III, S. 1713 ff., Jena 1908. - Biekel, Untersuchungen über den Einfluß von Affekten auf die Magensaftsekretion. Dtsch. med. Wochenschr. 31, 1829. 1905. - Bickel, Experimentelle Untersuchungen über die Magensaftsekretion beim Menschen. Dtsch. med. Wochenschr. 1906, S. 1323. - Biernacki, Die Bedeutung der Mundverdauung und des Mundspeichels für die Tätigkeit des gesunden und kranken Magens. Zeitschr. f. klin. Med. 21. 1892. - - B idder u. S chmidt, Die Verdauungssäfte und der Stoffwechsel. Leipzig 1852. - Blondlot, Traité analytique de la digestion. 1843. Bofinger, Über nervöse Dyspepsie. Arch. f. Verdauungskrankh. 16, H. 3. 1910. - Bogen, Experimentelle Untersuchungen über die psychische und assoziative Magensaftsekretion beim Mensehen. Jahrb. f. Kinderheilk. 65, H. 6. 1907. Boldireff, Die Hervorrufung künstl. bedingter (psychischer) Reflexe und ihre Eigenschaften. Arbeiten d. Gesellsch. russ. Ärte, Januar 1906. Ref. Biophys. Zentralbl. 2, Nr. 2. 1906. - Chigin, Activité sécrétoire de l'estomac du chien. Arch. des sciences biol. Petersburg, 1894. 3, - Gerwer, Über den Einfluß des Gehirns auf die Sekretion des Magensaftes. Obosren psihiatr. 1900. — Granda uer, Der hemmende Einfluß der Psyche auf die Sekretion des menschl. Magensaftes usw. Dtsch. Archiv f. klin. Medizin 101, 302. 1911. - Herz und Sterling, Untersuchung über psychisch bedingten Magensaft bei einem gastrostom. Kranken (Polnisch). Ref. Arch. f. Verdauungskr. 16, H. 1. - Horn bog, Beiträge zur Kenntnis der Absonderungsbedingungen des Magensaftes beim Menschen. Skandin. Arch. f. d. ges. Physiol. 15, 209. 1901. -- Karplus und Kreidl, Gehirn und Sympathicus. Arch. f. d. ges. Physiol. 135. 1910. 143. 1911. - Kascherininowo, Referiert Biophys. Zentralbl. 2, Nr. 2. 1906. - Longet, Traité de physiol. 1868. - Nikolai, Die physiol. Methodik der Tierpsyche. Journ. f. Psychol. u. Neurol. 10, H. 1, 2. - Pawlow und Schu mowa-Simonowskaja, Die Innervation der Magendrüsen beim Hunde. Zentralbl. f. Physiol. 1889, H. 6. - Pawlow, Die Arbeit der Verdauungsdrüsen. Wiesbaden 1898. - Pawlow, Psychische Frregung der Speicheldrüsen. Asher-Spiro, Ergebnisse der Physiol. I, S. $177 \mathrm{ff} .-$ Richet, Du suc gastrique chez l'homme et les animaux. Paris 1878. - Roeder und Sommerfeld, zit. nach Bickel. - Rollet, Untersuchungen a. d. Institut für Physiol. u. Histol. in Graz. 1871. - Sanotzki, Sür les stimulants de la sécrétion du suc gastrique. Arch. des scienc. biol. Petersburg 1, 1892. - Schrottenbach, Beiträge zur Kenntnis der Übertragung vasovegetativer Funktionen im Zwischenhirn. Zeitsehr. f. d. ges. Neurol. u. Psychiatr. 23, H. 4/5; 33, H. 3/4. Schüle, zit. nach Hornbog. - Skray, Über den Einfluß des Kauaktes und über die Wirkung psychischer Faktoren auf die Beschaffenheit des Mageninhaltes usw. Arch. f. Verdauungskrankh. 18. 1912. - Sticker, Wechselbeziehungen zwischen Speichel und Magensaft. Volkmanns Sammlung klin. Vortr. Nr. 297. - Tichimirow, Ein Versuch streng objektiver Untersuchung des Großhirns. Dissertation. Petersburg. - Troller, Über Methoden zur Gewinnung reinen Magensekretes. Zeitschr. f. klin. Med. 38, 1898. - Umber, Berl. klin. Wochenschr. 1905. - Wassilieff, Ref. Biophys. Zentralbl. 2, Nr. 2. 1906. - Woskoboinikowa-Grauström, Referiert Biophys. Zentralbl. 2, Nr. 2. 1906. Wright, Der Speichel, Ecksteins Handbibliothek des Auslandes, Wien 1844. 